\title{
Impacto del discurso político en la difusión de bulos sobre Covid-19. Influencia de la desinformación en públicos y medios
}

\section{Impact of political discourse on the dissemination of hoaxes about Covid-19. Influence of misinformation in public and media}

Concha Pérez-Curiel. Universidad de Sevilla. España.

cperez1@us.es

$[\mathrm{CV}] \bigcirc \mathrm{G} \mathrm{R}^{\circ} \mathrm{O}$

Ana María Velasco Molpeceres. Universidad de Valladolid. España. anamaria.velasco.molpeceres@uva.es $[\mathrm{CV}] \odot \mathrm{G}$

Cómo citar este artículo / Referencia normalizada

Pérez-Curiel, C. y Velasco Molpeceres, A. M. (2020). Impacto del discurso político en la difusión de bulos sobre Covid-19. Influencia de la desinformación en públicos y medios. Revista Latina de Comunicación Social, 78, 65-97. https://www.doi.org/10.4185/RLCS-2020-1469

\begin{abstract}
RESUMEN
Introducción: El desorden informativo generado por la Covid-19 dibuja un escenario estratégico para la difusión de la falacia y la propaganda política. Las redes sociales, en modo eco-chamber, reproducen el discurso gubernamental de la confusión y la mentira y favorecen un clima de desinformación, desestabilizador de las democracias. En paralelo, los públicos digitales se instalan como prosumidores del bulo político en Twitter y se atisba una tendencia de los medios a combatir las fake news. Metodología: El objetivo principal es conocer qué marcas de desinformación identifican el mensaje del líder, qué papel juegan las audiencias en la producción y difusión de lo falso y qué procesos de verificación desarrollan las agencias de fact-checking (Pagella Politica, Maldito Bulo, Full Fact y PolitiFact) y los medios (La Repubblica, El País, The Guardian y The New York Times) en una situación de máximo riesgo. Sobre una muestra compuesta por tweets publicados por los presidentes de gobierno $(n=272)$, noticias relacionadas con la Covid-19 $(\mathrm{n} 1=4.543)$ y bulos detectados en Twitter $(\mathrm{n} 1=200)$ diseñamos una metodología de análisis de contenido cuantitativo-cualitativo y análisis crítico del discurso político. Se emplea el software SPSS de estadística aplicada. Resultados, discusión y conclusiones: Los resultados revelan el protagonismo de un lenguaje político falaz, que favorece la producción del bulo en la red y requiere la efectividad del sistema de fact-checking de agencias internacionales y medios de comunicación, para combatir lo falso, siempre, y más si cabe en momentos de una pandemia sanitaria sin precedentes.
\end{abstract}

PALABRAS CLAVE: Covid-19; Discurso Político; Fake News; Bulo; Desinformación; Factchecking; Twitter; Periodistas 


\begin{abstract}
Introduction: The information disorder generated by Covid-19 paints a strategic scenario for the dissemination of the fallacy and political propaganda. Social networks, in eco-chamber mode, reproduce the government's discourse of confusion and lie and favor a climate of destabilizing disinformation in democracies. In parallel, digital audiences are installed as prosumers of the political hoax on Twitter and a tendency of the media to combat fake news is seen. Methodology: The main objective is to know which disinformation brands identify the leader's message, what role audiences play in the production and dissemination of the false and what verification processes are carried out by fact-checking agencies (Pagella Politica, Maldito Bulo, Full Fact and PolitiFact) and the media (La Repubblica, El País, The Guardian and The New York Times) in favor of the reliability of the public in a situation of maximum risk. On a sample composed of tweets published by the presidents of government $(n=272)$, news related to Covid-19 $(n 1=4,543)$ and hoaxes detected on Twitter $(\mathrm{n} 1=200)$, we designed a methodology for quantitative-qualitative content analysis and critical analysis of political discourse. SPSS applied statistics software is used. Results, discussion and conclusions: The results reveal the prominence of a fallacious political language, which favors the production of hoaxes on the Internet and requires the effectiveness of the fact-checking system of international agencies and the media, to combat the false, always, and more if possible in moments of an unprecedented health pandemic.
\end{abstract}

KEYWORDS: Covid-19; Political speech; Fake News; Hoax; Desinformation; Fact checking; Twitter; Journalists

\title{
CONTENIDO
}

1. Introducción. 2. Metodología. 3. Resultados. 4. Conclusiones. 5. Bibliografía.

\section{Introducción}

La trascendencia y los efectos de la Covid-19 serán difíciles de cuantificar incluso en el marco de una sociedad avanzada, dominada por los algoritmos y la inteligencia artificial (Xifra, 2020; Hansen et al., 2017; Powers y Kounalakis 2017). La ciudadanía, ante una situación de caos, ansiedad y confusión (Brennan, 2014) incrementa su interés por el consumo de noticias a través de las redes sociales (Newman et al., 2019), en un contexto adverso marcado por el desprestigio y la desconfianza en las élites y los medios de comunicación (Shearer y Gottfried, 2017). A su vez, se enfrenta a un fenómeno de máximo riesgo como la desinformación, analizado por los teóricos de la comunicación y del periodismo desde hace décadas (Salaverría et al., 2020). Definida como una acción en la que el emisor tiene el firme propósito de ejercer algún tipo de influencia y control sobre sus receptores para que éstos actúen conforme a sus deseos (Rodríguez Andrés, 2017), la desinformación se instala como estrategia comunicativa que afecta a múltiples dimensiones sociales como el sistema político, las relaciones internacionales o los asuntos públicos derivados de la salud (Brennen et al., 2020).

La implosión de una situación crítica y de riesgo para la población mundial, como la provocada por la Covid-19, ligada a niveles de máxima inseguridad e incertidumbre, ha disparado los índices de fake news y de bulos en las redes (Pérez-DaSilva et al., 2020). Las primeras investigaciones (Nielsen et al., 2020 ) ya recogían resultados de encuestas ( $\mathrm{N}=8502)$ entre usuarios de seis países -Alemania, Argentina, Corea del Sur, España, Estados Unidos y Reino Unido- conducida por el Reuters Institute for the Study of Journalism (marzo de 2020), que constata que un tercio de los encuestados afirma haber visto mucha o muchísima información falsa o engañosa en la última semana, sobre todo en la 
redes y en los servicios móviles de mensajería, un efecto también estudiado en otros contextos (Casero Ripollés, 2020; López-Borrull, Vives-Gràcia y Badell, 2018).

Para referirse al amplio universo de las informaciones falsas o erróneas que circulan por el entramado comunicativo, se han usado, entre otras, las expresiones de "fake news" definida como "información engañosa o incorrecta, que pretende ser una noticia real sobre política, economía o cultura" (Harsin, 2018) y de bulo o mensaje falso fabricado en las redes por usuarios y/o colectivos a fin de crear un determinado estado de opinión (Aparici, García-Marín y Rincón-Manzano, 2019). Tal ha sido la magnitud de fake news difundidas sobre la Covid-19 que la Organización Mundial de la Salud (2020) ha manifestado que nos encontramos ante una sobreabundancia de información falsa (Pérez Dasilva, Meso Ayerdi y Mendiguren Galdospín, 2020) que hace que algunas personas tengan dificultades para encontrar recursos fidedignos o guías de confianza cuando los necesitan (Aleixandre-Benavent et al., 2020). Este fenómeno definido por la OMS como infodemia está obstaculizando las medidas de contención del brote, propaga el pánico, crea confusión de forma innecesaria y genera división en un momento en el que necesitamos ser solidarios y colaborar para salvar vidas para poner fin a esta crisis sanitaria (Adhanom-Ghebreyesus; Ng, 2020).

En el ámbito de la Política, la influencia de las fake news sobre la ciudadanía ha sido identificada en procesos democráticos como las elecciones presidenciales en Francia (2017), en los procesos electorales de 2018 en Italia y México o en el referéndum sobre la permanencia del Reino Unido en la Unión Europea (2016) o el plebiscito sobre el acuerdo de paz en Colombia (2016) (Parra y Oliveira, 2018), aunque el clímax de producción de fake news se alcanza en la campaña por las elecciones presidenciales en Estados Unidos( 2016) en la que las historias inventadas que favorecían a Trump se compartieron 30 millones de veces, cuadruplicando la cantidad de acciones a favor de Hillary Clinton (Allcott y Gentzkow, 2017).

Durante la propagación de la pandemia de la Covid-19 en Europa asistimos a una sobreexposición de información política, derivada de las múltiples comparecencias públicas de los líderes gubernamentales, dada la necesidad de explicar a la ciudadanía lo que está sucediendo, cuáles son los riesgos y de implicarla en la solución, lo que convierte a la comunicación en una importante aliada de la gestión política, social, institucional y sanitaria (Costa Sánchez y López García, 2020). Sucede en un contexto político caracterizado por el aumento de prácticas de propaganda computacional (Rodríguez-Fernández, 2019; Redondo, 2016) dirigidas a: 1) Generar comentarios, positivos para reforzar posiciones y negativos para mermar al contrario o desviar la atención sobre un asunto; 2) Etiquetar a personas relevantes que participen en la conversación relacionada; 3) Patrocinar cuentas, webs y aplicaciones que contribuyan en la difusión de los mensajes; 4) Usar cuentas falsas y propaganda computacional (astroturfing) con el ánimo de manipular la conversación en red y 5) Crear contenido que contribuya a soportar la estrategia digital (Bradshaw y Howard; 2017). Una dinámica que promueve los desórdenes informativos y reabre el debate sobre la desprotección de los ciudadanos ante la difusión de los bulos (Aparici et al., 2019) que en situaciones de shock colectivo pueden afectar gravemente a la estabilidad social y a los cimientos mismos sobre los que se asientan las democracias occidentales (Amat et al., 2020).

El rol de los políticos como emisores de falacias (Patwari et al., 2017; Dale y Talaga, 2016; Naderi y Hirst, 2018) y la influencia que ejercen en los usuarios de las redes (Powers y Kounalakis, 2017; Weedon, et al., 2017) se convierte en un asunto de interés para la investigación científica, especialmente en una situación de crisis en el que se disparan los niveles de propagación de lo falso. Inmersos en una sociedad de riesgo global (Beck, 2002), identificada por un cambio en los modelos de producción informativa, de nuevas narrativas y de inteligencia artificial, urge el estudio del discurso político en la comunicación de la Covid-19. La información política deriva en una 
activación de mensajes institucionales sobre el coronavirus, a menudo no comprobados, que se convierten en caldo de cultivo para los usuarios anonimizados de la red. En esta disyuntiva, es necesario analizar la función de verificación que desarrollan las agencias de fact-checking (Mantzarlis, 2018) y el tratamiento informativo de las noticias publicadas sobre la Covid-19 en la prensa digital. Esta labor de comprobación y contraste de fuentes, de localización de antecedentes de los hechos, de contextualización de la información y de uso de un lenguaje divulgativo por parte de los periodistas forma parte de un proceso que persigue garantizar la veracidad de los hechos y devolver la confiabilidad de los públicos hacia los medios de comunicación (Bennett y Pfetsch, 2018).

A partir de una metodología de análisis de contenido cuantitativo, cualitativo y discursivo comparado (Sillverman, 2016; Krippendorff, 2004; Neuendorf, 2002; Nocetti, 1990; Van Dijk, 2015; Flowerdew y Richardson, 2017), aplicada sobre los tweets difundidos en Twitter por los presidentes de gobierno de EEUU, Italia, Reino Unido y España, sobre los bulos relacionados con la política, detectados por las principales agencias de fact-checking y sobre las noticias publicadas sobre Covid-19 en la prensa digital de referencia de estos países, se pretende responder a los siguientes objetivos:

O1. Identificar los recursos de falacia y propaganda en el discurso de los líderes políticos sobre el coronavirus.

O2. Analizar el papel de los usuarios de cuentas particulares en Twitter como productores y emisores de bulos y fakes news sobre información política.

O3. Comprobar qué recursos y técnicas de verificación utilizan las agencias de fact-checking y la prensa para localizar y desmentir los bulos e incrementar el nivel de veracidad de las noticias publicadas sobre la Covid-19.

\subsection{Política institucional y desinformación sobre la Covid-19}

La pandemia de la Covid-19 provoca una situación de crisis social, sanitaria, política y económica que ha puesto a prueba los sistemas de producción científica (Kupferschmidt, 2020) y ha generado un clima de preocupación en el entorno de las instituciones (Xifra, 2020) y de los medios (TorresSalinas; 2020) sobrepasados por la eclosión de rumores, falacias y desinformación. La implosión del Big Data (Hansen et al., 2017) y el uso de bots (Chu et al., 2012) y trolls (Jamison et al., 2019) incide en la superabundancia informativa (Xifra, 2020), que se intensifica en momentos de crisis sanitarias de impacto (Mayo Cubero, 2020).

Origen del virus, expectativas ante la vacuna, progresión del brote de enfermedades infecciosas o medidas preventivas han sido objeto de bulos y desinformación en crisis anteriores (Broniatowski et al., 2018; Cheng et al., 2018; Wang et al., 2017; Ghenai y Mejova, 2017; Dredze et al., 2016), que han tenido como productores y emisores a una audiencia activa (Guidry et al., 2017) y experta en la viralización de lo fake gracias a mecanismos que resisten los filtros y el control de las desinformaciones (Powers y Kounalakis, 2017).

Para luchar contra la desinformación, numerosas instituciones gubernamentales han publicado páginas especiales que incluyen refutaciones específicas sobre los mitos más recurrentes y perjudiciales en torno a la crisis. La Comisión Europea recomienda seguir el consejo de las autoridades de salud pública y de los sitios web de las organizaciones internacionales y de la Unión Europea pertinentes (como European Centre for Disease Prevention and Control y Organización Mundial de la Salud), así como no compartir información no verificada procedente de fuentes dudosas (Comisión Europea, 2020). Sin embargo, y a pesar de las declaraciones de buenas 
intenciones que han presidido los discursos institucionales, la práctica de la desinformación sigue de permanente actualidad tanto en la comunicación política como en las relaciones internacionales (Rodríguez Andrés, 2017). En las elecciones presidenciales de Estados Unidos en 2016, se llegó a cuestionar de manera pública si su injerencia habría contribuido a que Trump saliera elegido presidente (Allcott y Gentzkow; 2017). En esta línea, se ha observado que los efectos son más pronunciados en contenidos de política que en terrorismo, desastres naturales, ciencia, leyendas urbanas o información financiera (Vosoughi; Roy; Aral, 2018).

En el escenario del Covid-19, las comparecencias públicas de los presidentes de gobierno organizadas a raíz de la propagación del coronavirus son una muestra del uso de desinformación y de falacia por parte de los líderes políticos, un hecho que se ha convertido en motivo de debate político. En España, durante las primeras semanas del estado de alarma decretado por el Gobierno, los partidos políticos se cruzaron acusaciones mutuas de difundir bulos y noticias falsas (El País, 9 abril 2020). Muchos de estos mensajes falaces se derivan a plataformas digitales como Facebook, que ha procedido a alertar en sus muros de la retirada de contenidos engañosos (Rosen, 2020) o Google y Twitter que han tomado medidas para ofrecer mayor visibilidad a la información oficial y reducir la exposición de sus usuarios a contenidos no verificados.

En cualquier caso, la desinformación registra una tendencia creciente. Según un informe de Corporate Excellence (2018), en 2017 las fake news aumentaron un 365\% y la tendencia es positiva. La consultora Gartner (Panetta, 2017) prevé que en 2022 el público occidental consumirá más noticias falsas que verdaderas. Por tanto, luchar contra la desinformación es ya un objetivo institucional no sólo en el ámbito político sino también mediático.

\subsection{La verificación informativa. Un ejercicio de calidad periodística}

La desinformación es hoy un tema candente que ha puesto en el punto de mira el desempeño de los consultores políticos, los medios de comunicación y los responsables de redes sociales. Se añaden los verificadores, erigidos como garantes de la veracidad, que ofrecen una nueva área de especialización al sector (Rodríguez-Fernández, 2019; Bernal-Triviño y Clares-Gavilán, 2019; Magallón-Rosa, 2018).

El esmero en la precisión de los datos viene de antiguo en el periodismo: las secciones de verificación de medios como Time o de The New Yorker, y los propios controles de los procesos de edición periodística, eran y son de facto procesos de verificación. La novedad está en que las plataformas no son departamentos de una redacción que corrigen errores antes de publicar un artículo. Por su alcance planetario, la pandemia ha trascendido a estas plataformas especializadas y se ha convertido en un tema que acapara gran cantidad de comprobaciones en las plataformas de verificación periodística o de temática más general. Los expertos hablan de un crecimiento masivo de fact-checks con motivo de la Covid-19 (Brennen et al., 2020).

El periodismo y la verdad que encierra su ejercicio son herramientas imprescindibles para identificar y denunciar las historias falsas (Marcos-Recio, 2017). En un momento en el que los organismos gubernamentales centran sus esfuerzos en luchar contra la enfermedad, los profesionales de la información deben jugar un papel relevante para detener la propagación de la información errónea relacionada con la pandemia (Tandoc, 2020). Por ejemplo, algunos líderes mundiales como Donald Trump anunciaron que un medicamento utilizado para combatir el paludismo, la cloroquina y su derivado la hidroxicloroquina, eran eficaces para combatir la Covid-19 (Chadwick; Cereceda, 2020; Larson, 2020). Sin embargo, un estudio publicado el 30 de marzo de 2020 por Cochrane indicaba que los resultados de los ensayos clínicos que habían evaluado su eficacia en el tratamiento de la 
Covid-19 eran poco concluyentes y que había que interpretarlos con cautela por las limitaciones en su diseño (Cochrane Iberoamérica, 2020).

Ahora más que nunca, el periodismo necesita incentivar la calidad y la credibilidad mediante refuerzos en el proceso de verificación, con el objetivo de evitar o mitigar los efectos de la proliferación de las noticias falsas, cuyo tráfico en las redes aumenta, dado el anonimato que éstas posibilitan (Vázquez-Herrero et al., 2019). La búsqueda de declaraciones verificables a través de la consulta de grabaciones parlamentarias, medios de comunicación y redes sociales (1), la localización de los hechos originales mediante la consulta de la mejor fuente disponible (2) y la corrección del contenido mostrando las pruebas disponibles mediante una escala de veracidad (3) son las tres fases principales del proceso de verificación (Mantzarlis, 2018). En estos momentos, el periodismo asiste a un nuevo reto provocado por la eclosión de noticias sobre la Covid-19, en el que es preciso garantizar la veracidad y el contraste de fuentes, frenar el consumo informativo incontrolado y ofrecer recursos para desmontar la falacia y el efecto de las fake news.

A partir de diferentes clasificaciones aportadas por expertos (López-Borrull, et al., 2018, Nielsen; Graves, 2017; Nielsen; Graves 2017; Wardle, 2017; Zimdars, 2016) se diseña una catalogación que muestra tipología de fake news y procesos de verificación en los dos ámbitos de estudio.

Tabla 1. Catalogación de Fake News y Códigos de Verificación

\begin{tabular}{|c|c|c|c|}
\hline \multicolumn{2}{|c|}{ Verificadores de Agencias } & \multicolumn{2}{|l|}{ Verificadores de Medios } \\
\hline Tipología & Códigos de Verificación & Tipología & Códigos de verificación \\
\hline $\begin{array}{l}\text { Fake news } \\
\text { Sátira } \\
\text { Sesgo Extremo } \\
\text { Teoría de la } \\
\text { Conspiración } \\
\text { Rumor } \\
\text { State News } \\
\text { Pseudociencia } \\
\text { Hate news } \\
\text { Clickbait } \\
\text { Proceda con } \\
\text { precaución } \\
\text { Verificación } \\
\text { Política }\end{array}$ & $\begin{array}{l}\text { - Noticia falsa } \\
\text { - Montaje } \\
\text { - Corresponde a otra } \\
\text { fecha } \\
\text { - Corresponde a otro } \\
\text { lugar } \\
\text { - Autoría del bulo: } \\
\text { anónima o identificada } \\
\text { - Nivel de Fiabilidad } \\
\text { - Nivel de autoridad } \\
\text { - Nivel de impacto e } \\
\text { interacción } \\
\text { - Temática } \\
\text { - Recursos de énfasis } \\
\text { - Marcas de Falacia }\end{array}$ & $\begin{array}{l}\text { Periodismo Superficial } \\
\text { Parodia } \\
\text { Provocación } \\
\text { Partidismo } \\
\text { Búsqueda de influencia } \\
\text { política } \\
\text { Provecho } \\
\text { Sensacionalismo } \\
\text { Falta de precisión } \\
\text { Contenido hiperpartidista } \\
\text { Uso de la propaganda } \\
\text { Uso de la mentira política } \\
\text { Esponsorización }\end{array}$ & $\begin{array}{l}\text { - Distinguir } \\
\text { Hechos/Opiniones } \\
\text { - Evitar sites y enlaces } \\
\text { fake } \\
\text { - Incluir antecedentes y } \\
\text { Contexto } \\
\text { - Situar los hechos: } \\
\text { fecha/lugar } \\
\text { - Garantizar el uso de } \\
\text { más de una fuente. } \\
\text { - Evitar el uso de fuentes } \\
\text { conflictivas } \\
\text { - Usar un lenguaje } \\
\text { divulgativo }\end{array}$ \\
\hline
\end{tabular}

Fuente: elaboración propia

La labor de verificación de fact-checkers de agencias y periodistas de medios muestra diferencias y similitudes, aunque refleja un denominador común: conocer el amplio espectro de recursos que promueven el discurso de la mentira y provocan un incremento cada vez más acentuado de las fake news y mejorar los procesos para combatirlas mediante protocolos de comprobación que puedan ayudar a los usuarios a reconocer lo falso y a actuar en consecuencia. 


\subsection{Cronología de la Covid-19. Principales indicadores de contexto.}

A finales del mes de enero de 2020 la Organización Mundial de la Salud declaró el brote de coronavirus 2019-nCoV como emergencia de salud pública de interés internacional, que elevó a pandemia (11 de marzo 2020) tras los alarmantes niveles de propagación desde su origen en la ciudad china de Wuhan con más de más de 118.000 casos, en 114 países, y 4.291 muertes (OMS, 2020).

El foco europeo de la pandemia se inicia en Italia, lo que obliga al presidente Giuseppe Conte, por el Decreto Ley del 2 de marzo, a aumentar las restricciones y a anunciar el confinamiento de todo el país (9 de marzo). En España, Pedro Sánchez, presidente del Gobierno declara el estado de alarma (14 de marzo)) en una situación de máxima emergencia afirmando: "No nos va a temblar la mano para ganar al virus. Ponemos en el centro de nuestras prioridades la salud de las personas, pero al mismo tiempo debemos atender directamente a nuestras familias, trabajadores, a los autónomos y a las empresas"1. En el caso de Reino Unido y EEUU, la comunidad científica cuestiona la efectividad de las medidas anunciadas por Boris Johnson publica el informe Report 9: Impact of nonpharmaceutical interventions (NPIs) to reduce Covid-19 mortality and healthcare demand ${ }^{2}$, que sostiene que en ausencia de una vacuna Covid-19 se deben evaluar medidas de salud pública, conocidas como intervenciones no farmacéuticas (ISFL), que combinan el aislamiento domiciliario, la cuarentena y el distanciamiento social de los ancianos y personas de riesgo, complementándose en su caso con el cierre de escuelas y universidades. En EEUU, el 13 de marzo, dos días después de que la OMS calificara de pandemia el brote de la Covid-19, el presidente Donald Trump proclama la emergencia nacional en todo el país ${ }^{3}$.

\section{Metodología}

Ante un panorama de desconcierto mundial donde multiplica la publicación de decretos gubernamentales sobre estados de alarma y confinamiento de la población, interesa analizar el discurso de los principales representantes de la política mundial y la proyección de estos mensajes en Twitter y en la prensa de referencia de sus respectivos países. A este escenario hay que añadir la celebración de campañas electorales (en el caso de Estados Unidos) como factores de influencia en la comunicación de la crisis.

El análisis metodológico se rige por un principio de causa-efecto: los políticos difunden en Twitter mensajes identificados por la falacia y la propaganda (1); influyen en los usuarios digitales que producen y viralizan bulos y fake news en la red (2); las agencias de fact-checking denuncian estos bulos, siguiendo procesos de comprobación de lo falso (3); los periódicos digitales publican noticias sobre la Covid-19, relacionadas con la política o los políticos, objeto de estudio y aplican mecanismos para la verificación y el contraste informativo (4). Desde este enfoque de causalidad se plantean las siguientes preguntas de investigación:

PI1. ¿Se considera la desinformación una característica del discurso político sobre la Covid-19 en Twitter?

PI2. ¿En qué medida los usuarios de las cuentas particulares de Twitter favorecen la difusión de bulos y fake news sobre el coronavirus?

PI3. ¿Qué papel ejercen las agencias de fact-checking y los periodistas y qué filtros proponen para verificar la información y combatir las fake news?

\footnotetext{
${ }^{1}$ https://www.lamoncloa.gob.es

2 https://www.imperial.ac.uk/media/imperial-college/medicine/mrc-gida/2020-03-16-COVID19-Report-9.pdf

3 www.whitehouse.gov
} 
La investigación se sustenta en dos perspectivas metodológicas complementarias como el análisis de contenido cuantitativo-cualitativo (Silverman, 2016; Krippendorff, 2004; Neuendorf, 2002) y el análisis del discurso (Nocetti, 1990; Van Dijk, 2015; Flowerdew y Richardson, 2017) que permitan identificar por un lado, los mensajes políticos considerados como bulos por las agencias de factchecking (@PolitiFact, @PagellaPolítica,@FullFact y @malditobulo)y definir sus características y, por otro, observar cómo se han trasladado estas desinformaciones al entorno de la prensa internacional $^{4}$.

El criterio para establecer la muestra general se basa en diferentes hitos publicados por la OMS y por la UE durante el mes de marzo: La OMS declara la pandemia global por la Covid-19 (11 de marzo), La $O M S$ informa que Europa se ha convertido en el epicentro de la pandemia (13 de marzo) y La presidenta de la Comisión Europea Ursula Von der Leyen llama a la "lucha contra la desinformación" (31 de marzo). El muestreo específico se concentra en el periodo comprendido entre el 11 y el 27 de marzo, seleccionando a los países que registraron en esa franja el mayor índice de contagiados a nivel europeo y mundial (OMS, 2020; Consejo Europeo, 2020). Así mismo y dado el ámbito político en el que se centra el estudio, se elige a los máximos representantes de estos países: Giuseppe Conte (Italia), Pedro Sánchez (España), Boris Johnson (Gran Bretaña) y Donald Trump (Estados Unidos), con el fin de analizar desde la óptica del análisis crítico del discurso, el uso de recursos de falacia y propaganda que utilizan en sus mensajes de Twitter y la influencia en la producción de bulos por parte de los usuarios de la red.

Se opta por Twitter, una plataforma utilizada, entre otros, por políticos, partidos, gobiernos, organizaciones internacionales, agentes del tercer sector, la sociedad civil y los medios de comunicación. Desde su nacimiento en 2006, ha tenido una importancia creciente en las campañas electorales y ha sido aplicado en una amplia gama de contextos políticos - locales, nacionales e internacionales-, (Campos Domínguez, 2017), que lo convierten en una herramienta consolidada para la comunicación política frente a Facebook, Youtube o Instagram.

El criterio de selección de agencias de fact-checking (Pagella Politica ${ }^{5}$, Maldito Bulo ${ }^{6}$, Full Fact ${ }^{7}$ y PolitiFact $^{8}$ ) responde a su pertenencia a la Red Internacional de Verificación de Datos (IFCN) ${ }^{9}$, así como a la trayectoria y la referencia científica en la verificación de información falsa sobre temas específicos de política y declaraciones de políticos ${ }^{10}$.Para la elección de cabeceras de prensa ( $L a$ Repubblica, El País, The Guardian y The New York Times) se ha recurrido a los resultados del informe de 2019 sobre noticias digitales del Reuters Institute de la Universidad de Oxford (Newman et al., 2019) además del criterio geográfico (prensa nacional e internacional) y el criterio temático (prevalencia de la información política sobre la Covid-19).

\footnotetext{
${ }^{4}$ www.nytimes.com, www.repubblica.it, www.theguardian.com y www.elpais.com

5 https://pagellapolitica.it/

6 https://maldita.es/malditobulo/

${ }^{7}$ https://fullfact.org/

8 https://www.politifact.com/

9 Fundada en 2015 por el Instituto Poynter (una referencia en la promoción de las buenas prácticas y la honestidad en la actividad periodística), la Red Internacional de Verificación de Datos nació para impulsar el fact checking y aunar los esfuerzos de las organizaciones de verificación. Cinco años después de su creación, la IFCN es hoy la mayor organización de fact checkers del mundo, una especie de red internacional contra los bulos. Sus funciones van de la formación para periodistas o la monitorización de tendencias en la verificación de hechos a la promoción de estándares básicos del fact checking, lo que han bautizado como el Código de Principios. https://ifcncodeofprinciples.poynter.org/signatories

${ }^{10}$ https://www.cac.cat/sites/default/files/2019-01/Q44_Revista_Webs_ES.pdf
} 
El universo de estudio está formado por representantes políticos gubernamentales, agencias de factchecking, medios y cuentas particulares de usuarios de Twitter y su papel respectivo en la producción, emisión, verificación y tratamiento informativo de las fake news y de los bulos publicados sobre el coronavirus. La muestra general comprende los mensajes difundidos en Twitter por los presidentes del gobierno de los países seleccionados sobre el coronavirus $(n=272)$ tweets), los bulos detectados por las diferentes agencias de fact-checking ( $\mathrm{n}=200$ bulos) y el total de noticias sobre Covid-19 publicadas por las distintas cabeceras digitales, objeto de estudio ( $\mathrm{n}=4.543$ noticias). De la muestra general se deriva muestra específica, acorde con palabras clave como "política" y/o políticos", una condición que reduce la muestra (197 tweets, 61 bulos y 68 noticias de prensa relacionadas directamente con esta temática) y la ajusta a indicaciones de modelos metodológicos previos (Baker 2006; Cleary et al., 2014; Silverman, 2016 o Khan et al., 2019), que recomiendan que, en la recopilación de datos en los estudios del discurso debe primar la calidad en lugar de la cantidad. Por tanto, la muestra no equivale a la totalidad de los bulos difundidos durante el período indicado, sino que refleja exclusivamente los que hacen referencia a contenidos y actores de la política, verificados por las cuatro plataformas seleccionadas.

Tanto los tweets de las cuentas de los líderes como los publicados por las agencias de fact-checking fueron descargados a través de T-Hoerder 17, que trabaja con una metodología denominada $t$ hoarder_kit, una evolución de la plataforma t-hoarder (Congosto, BasantaVal y Sánchez Fernández, 2017). El programa consiste en un conjunto de recursos con software de código abierto que permiten tanto la descarga como el procesamiento de la información de Twitter para facilitar el uso de herramientas de análisis y la visualización en redes.

Las noticias de prensa se han localizado a través de buscadores online ${ }^{11}$. La ecuación de búsqueda avanzada responde a: (coronavirus OR “covid-19" OR "2019-nCoV” OR "SARS-CoV-2" OR "CoVSARS-2” OR koronabirus) \& xoptions=contentfields=title:subtitle.

El programa estadístico elegido para el procesamiento de datos relacionados con las categorías definidas es el IBM SPSS Statistics, Versión 24. La fiabilidad de los intercodificadores se ha calculado con la fórmula Pi de Scott, alcanzando un nivel de error de 0,98. El método, apoyado en investigaciones previas sobre la calidad informativa y guía de buenas prácticas en el periodismo (Redondo, 2018) y en portales de catalogación de fuentes (opensources.com) permite estudiar los mecanismos de verificación desarrollados por agencias de fact-checking y medios, en un proceso paralelo o complementario.

El método se apoya en variables relacionadas con los perfiles que conforman el universo de estudio: líderes políticos, usuarios de Twitter y verificadores de la información publicada sobre el coronavirus.

\footnotetext{
${ }^{11}$ https://www.mynews.es/, https://www.kioskoymas.com y https://www.kiosko.net/
} 
RLCS, Revista Latina de Comunicación Social, 78, 86-119

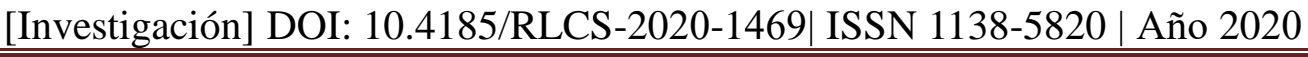

Tabla 2. Codificación de Fuentes y Tipología de Variables

\begin{tabular}{|c|c|c|c|c|}
\hline $\begin{array}{l}\text { Productores de } \\
\text { Desinformación }\end{array}$ & $\begin{array}{l}\text { Agencias } \\
\text { de } \\
\text { checking }\end{array}$ & Prensa Digital & $\begin{array}{l}\text { Variables } \\
\text { Cuantitativas/Cualitativas }\end{array}$ & Variables Discursivas \\
\hline $\begin{array}{l}\text { - Líderes } \\
\text { políticos } \\
\text { - Usuarios } \\
\text { particulares }\end{array}$ & $\begin{array}{l}\text { - Pagella } \\
\text { Politica } \\
\text { - Maldito Bulo } \\
\text { - Full Fact } \\
\text { - PolitiFact }\end{array}$ & $\begin{array}{l}\text { - La Repubblica } \\
\text { - El País } \\
\text { - The Guardian } \\
\text { - The New York } \\
\text { Times } \\
\text { - Líderes } \\
\text { Políticos } \\
\text { - Prensa Digital }\end{array}$ & $\begin{array}{l}\text { Bulos y Fake News } \\
\text { - Temática } \\
\text { - Texto } \\
\text { - Imágenes } \\
\text { - Vídeos } \\
\text { Noticias } \\
\text { - Antecedentes } \\
\text { - No de fuentes } \\
\text { - Contexto } \\
\text { - Lenguaje }\end{array}$ & $\begin{array}{l}\text { - Falacias } \\
\text { - Mecanismos de } \\
\text { propaganda }\end{array}$ \\
\hline
\end{tabular}

Fuente: Elaboración propia

El análisis de variables genera la elaboración de tablas de contingencia y frecuencia relativas al tipo de fuentes, temática, y recursos propios del lenguaje político sobre la Covid-19 en el contexto de Twitter. Del mismo modo, los resultados reflejan los procesos de localización, denuncia y verificación de bulos y fake news desarrollados por las agencias de fact-checking y medios de comunicación, objeto de estudio.

\section{Resultados}

Con el fin de estructurar los resultados tras la aplicación de una metodología estadística combinada, se distinguen tres fases, relacionadas con los actores del proceso y la función que desarrollan como productores, emisores y consumidores de la información.

\section{Fase 1. Indicadores de desinformación en el discurso político de los presidentes de Gobierno}

En una situación de crisis como la dibujada por la pandemia se reproducen los niveles de intervención de los gobiernos, los partidos y los líderes políticos en los medios tradicionales y digitales. Una información rodeada de incertidumbre ante los efectos del virus, de falta de prevención y errores en la comunicación a la ciudadanía (López García, 2020) describen la radiografía política durante la Covid-19.

Para responder a la primera pregunta de investigación (PI1), analizamos en esta primera fase el papel de los políticos como productores y emisores de desinformación. Las declaraciones realizadas por los presidentes de gobierno en las diferentes convocatorias públicas para informar a la ciudadanía sobre la pandemia se proyectan en Twitter. Los máximos representantes institucionales publican un total de 197 tweets específicos sobre temas políticos y coronavirus recurriendo a estrategias de comunicación política y mecanismos de falacia y propaganda que puede aumentar los niveles de confusión e inseguridad de la audiencia social. 
Tabla 3. Codificación de falacias y recursos de la propaganda política ${ }^{12}$

\begin{tabular}{|c|c|c|c|c|c|c|c|c|c|c|}
\hline $\begin{array}{l}\text { Categor } \\
\text { ías }\end{array}$ & $\begin{array}{l}\text { @ Giuse } \\
\text { ppe } \\
\text { ConteIT } \\
\% \\
\text { dentro } \\
\text { de } \\
\text { Recurso } \\
\text { s }\end{array}$ & $\begin{array}{l}@ \text { Giuse } \\
\text { ppe } \\
\text { ConteIT } \\
\mathrm{N}^{\circ} \text { de } \\
\text { tweets/ } \\
197 \\
\text { total }\end{array}$ & \begin{tabular}{|l}
$@$ sanch \\
ezcastej \\
on \\
$\%$ \\
dentro \\
de \\
Recurso \\
s \\
\end{tabular} & $\begin{array}{l}\text { @ sanch } \\
\text { ezcastej } \\
\text { on } \\
\mathrm{N}^{\circ} \text { de } \\
\text { tweets/ } \\
197 \\
\text { total }\end{array}$ & $\begin{array}{l}\text { @ Boris } \\
\text { Johnson } \\
\% \\
\text { dentro } \\
\text { de } \\
\text { Recurso } \\
\text { s }\end{array}$ & \begin{tabular}{|l} 
@ Boris \\
Johnson \\
$\mathrm{N}^{\mathrm{o}}$ de \\
tweets/ \\
197 \\
total
\end{tabular} & \begin{tabular}{|l|}
$@$ Donal \\
d \\
Trump \\
$\%$ \\
dentro \\
de \\
Recurso \\
s \\
\end{tabular} & $\begin{array}{l}\text { @ Donal } \\
\mathrm{d} \\
\text { Trump } \\
\mathrm{N}^{\circ} \text { de } \\
\text { tweets/ } \\
197 \\
\text { total }\end{array}$ & $\begin{array}{l}\text { Valores } \\
\text { Medios }\end{array}$ & $\begin{array}{l}\mathrm{N}^{\mathrm{o}} \mathrm{de} \\
\text { tweets/ } \\
197 \\
\text { total }\end{array}$ \\
\hline $\begin{array}{l}\text { Apelaci } \\
\text { on } \quad \text { a la } \\
\text { autorid } \\
\text { ad }\end{array}$ & 14,3 & 28,1 & 14,7 & 28,9 & 20,5 & 40,3 & 21,4 & 42,1 & 17,7 & 34,8 \\
\hline 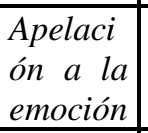 & 17,7 & 34,8 & 16,3 & 32,1 & 19,6 & 38,6 & 19,2 & 37,8 & 18,2 & 35,8 \\
\hline $\begin{array}{l}\text { Apelaci } \\
\text { on a la } \\
\text { ignoran } \\
\text { cia }\end{array}$ & 11,4 & 22,4 & 11,1 & 21,8 & 14,1 & 27,7 & 15,2 & 29,9 & 12,9 & 25,4 \\
\hline $\begin{array}{l}\text { Atribuci } \\
\text { ones }\end{array}$ & 5,1 & 10,0 & 5,5 & 10,8 & 6,4 & 12,6 & 6,5 & 12,8 & 5,8 & 11,4 \\
\hline Énfasis & 5,5 & 10,8 & 6,4 & 12,6 & 5,7 & 11,2 & 7,4 & 14,5 & 6,2 & 12,2 \\
\hline $\begin{array}{l}\text { Opinion } \\
\text { es como } \\
\text { hechos }\end{array}$ & 12,8 & 25,2 & 11,4 & 22,4 & 9,1 & 17,9 & 7,1 & 13,9 & 10,1 & 19,8 \\
\hline $\begin{array}{l}\text { Selecció } \\
n \quad d e \\
\text { informa } \\
\text { ción } \\
\end{array}$ & 16,8 & 33,0 & 16,7 & 32,8 & 9,2 & 18,1 & 7,3 & 14,3 & 12,5 & 24,6 \\
\hline \begin{tabular}{|l} 
Uso de \\
etiqueta \\
s
\end{tabular} & 16,2 & 31,9 & 17,8 & 35,0 & 15,2 & 29,9 & 15,8 & 31,1 & 16,2 & 31,9 \\
\hline
\end{tabular}

Fuente: elaboración propia

El uso generalizado de la falacia (Tabla 3) es una constante en los mensajes de todos los perfiles analizados. Los valores medios se concentran en las figuras de apelación a la emoción (18,2\%), apelación a la autoridad $(17,7 \%)$, uso de etiquetas $(16,2 \%)$ y apelación a la ignorancia $(12,9 \%)$, lo que se identifica con estrategias propias de situaciones de conflicto, de confrontación política y de producción de mensajes falsos.

En relación con los líderes, destacan los valores máximos alcanzados por Donald Trump en consonancia con su estrategia de publicación de más de 10 tweets diarios y de producción de fake news (Pérez Curiel y Limón Naharro, 2019). Los datos revelan además, diferencias entre los políticos conservadores, más afines a un discurso populista y los políticos que abanderan posiciones liberales e independientes.

En esta línea, Donald Trump (Partido Republicano) y Boris Johnson (Partido Conservador), alcanzan porcentajes referentes en apelación a la autoridad (21,4\%/20,5\%), relacionada con consignas falsas

\footnotetext{
12 La tabla hace referencia a porcentajes y número de tweets. Los porcentajes en negrita señalan la tipología de recursos más utilizados por los líderes políticos. En un mismo tweet puede aparecer más de un recurso.
} 
y teorías de conspiración contra otros países y apelación a la emoción (19,2\%/19,6\%), con un discurso dirigido a los sentimientos de los ciudadanos y a la necesidad de colaborar para vencer al virus.

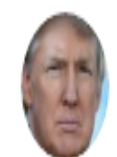

\section{Donald J.Trump \$ @realDonaldTrump. 18 mar.}

I always treated the Chinese virus very seriously, and have done a very good

job from the beginning, including my very early decision to close the

"borders" from China - against the wishes of almost all. Many lives were

saved. The Fake News new narrative is disgraceful \& false!

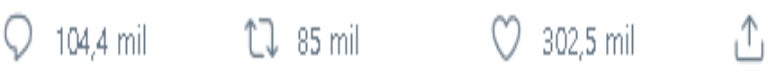

Imagen 1: Apelación a la autoridad, énfasis y apelación a la ignorancia

Fuente: https://twitter.com/realDonaldTrump/status/1240243188708839424?s=20

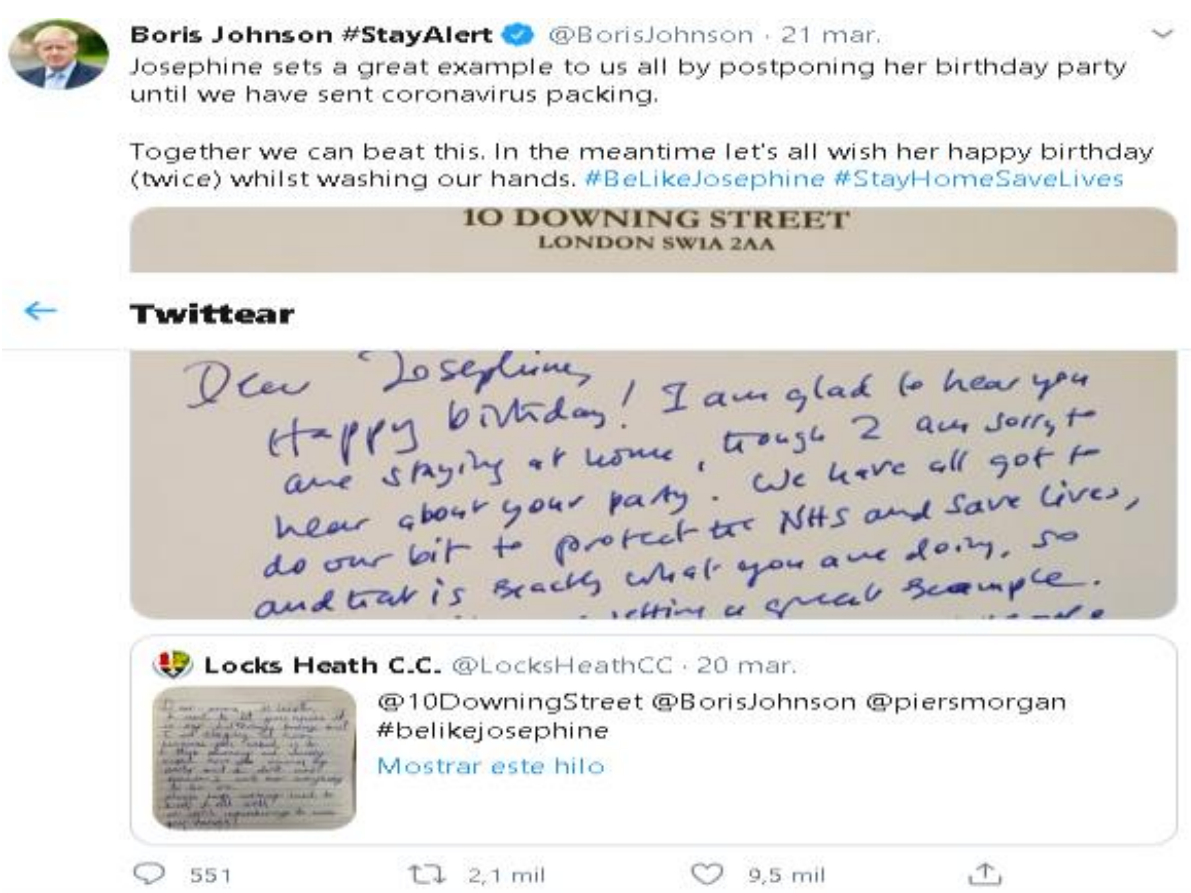

Imagen 2: Apelación a la emoción, apelación a la ignorancia y atribución

Fuente: https://twitter.com/BorisJohnson/status/1241348429546217475?s=20

En el caso de Donald Trump, los ataques se han concentrado en China, a la que culpa de la pandemia, en el expresidente Barak Obama, su predecesor, al que culpa de errores en el sistema de pruebas de los Centros para el control y prevención de enfermedades (CDC) o en los demócratas, como autores del engaño de la Covid-19. Para Boris Johnson, el discurso inicial de infravaloración de la enfermedad responde a hechos no contrastados o mensajes que anteponen la economía a la salud.

Frente a ellos, Giuseppe Conte (Independiente) y Pedro Sánchez (PSOE), se posicionan por delante en falacias como uso de etiquetas $(16,2 \% / 17,8 \%)$, selección de la información, $(16,8 \% / 16,7 \%)$ y opiniones como hechos $(12,8 \% / 11,4 \%)$, que pueden generar confusión ante la veracidad de los 
acontecimientos. En ambos casos, el discurso institucional intenta justificar la actuación ante la epidemia. Por ejemplo, en Italia, con la decisión de Conte de no aislar Bérgamo (Italia), una de las zonas más afectadas por el coronavirus o en España, con la afirmación de Sánchez sobre el impacto simétrico de la Covid en toda Europa, cuando los contextos, los casos y las actuaciones gubernamentales fueron distintos en cada país.

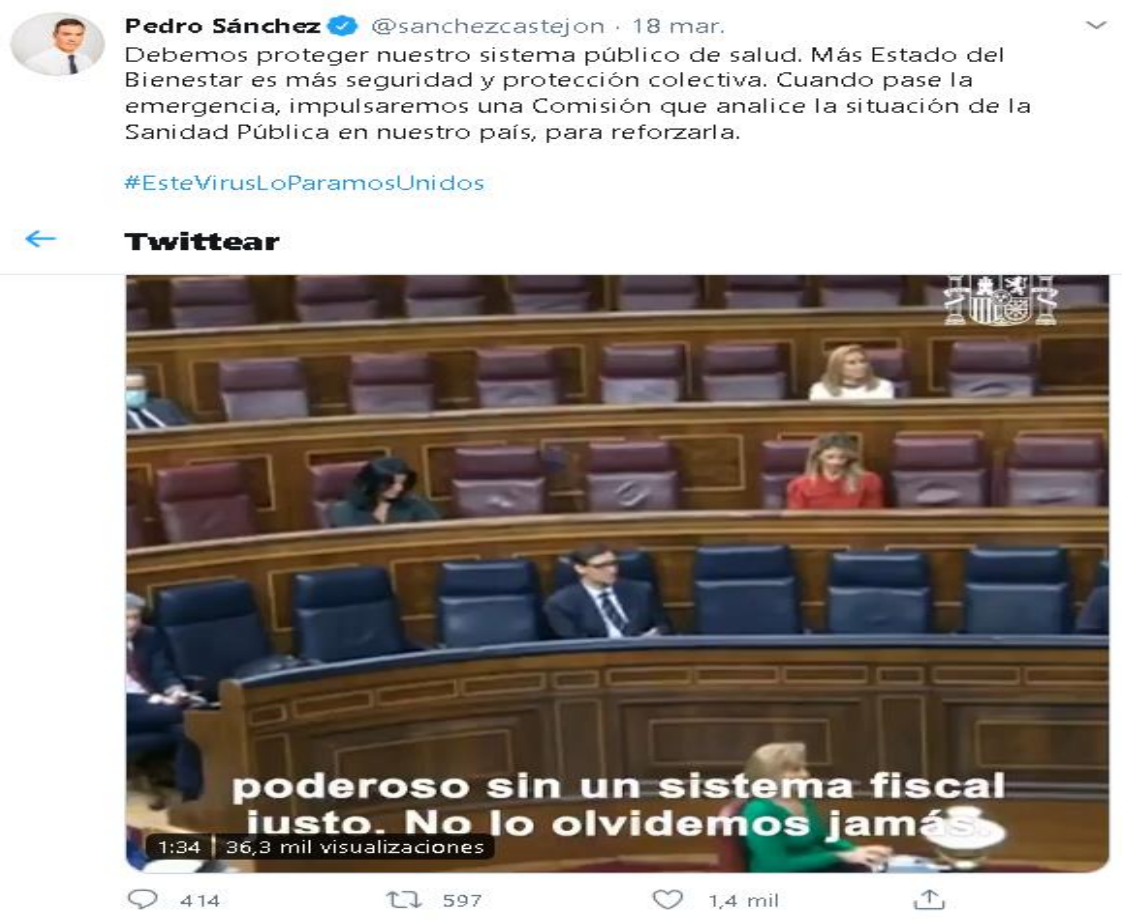

Imagen 3: Uso de etiquetas, opiniones como hechos, énfasis

Fuente: https://twitter.com/sanchezcastejon/status/1240218588725772293?s=20

\section{Giuseppe Conte @GiuseppeContelT.11 mar.}

II Consiglio dei Ministri ha approvato lo stanziamento straordinario di 25 miliardi di euro per far fronte alle difficoltà che il Paese sta vivendo a causa del \#coronavirus. Stiamo facendo tutto ciò che è necessario, con ogni strumento a disposizione. Insieme ce la faremo
$1,4 \mathrm{mil}$
〔】 3 mil
O $16,3 \mathrm{mil}$

\section{Imagen 4: Selección de la información}

Fuente: https://twitter.com/GiuseppeConteIT/status/1237694727203454976?s=20

Otros recursos como el énfasis $(6,2 \%)$ en el caso de Conte cuando insiste en la ayuda incondicional del gobierno a la población ${ }^{13}$ o de Boris Johnson $(5,7 \%)$ cuando se niega al cierre de colegios y espacios públicos porque no es momento de poner a prueba la resistencia de la población ${ }^{14}$ o el uso de atribuciones cuando Trump $(5,8 \%)$ acusa a los grandes medios de aprovechar el coronavirus para desprestigiarle ante las próximas elecciones ${ }^{15}$ o Sánchez $(5,5 \%)$ cuando afirma "yo soy el presidente

\footnotetext{
${ }^{13} \mathrm{https}: / /$ twitter.com/GiuseppeConteIT/status/1237792996743151622?s=20

14 https://elpais.com/sociedad/2020-03-13/la-estrategia-del-gobierno-de-johnson-contra-el-coronavirus-divide-a-lacomunidad-cientifica.html

${ }^{15}$ https://twitter.com/realDonaldTrump/status/1242905328209080331?s=20
} 
del Gobierno y asumo toda la responsabilidad" 16 refiriéndose a las medidas tomadas contra el coronavirus, identifican las marcas del discurso político en Twitter.

Estos resultados ponen de relieve el uso de un relato electoralista (Kaiser, 2020) que se sigue manteniendo o incluso aumentando en situaciones de emergencia sanitaria, provocando inseguridad y desconfianza en los públicos. La reacción de los usuarios de Twitter ante estos mensajes puede generar una cadena de noticias falsas, que tienen como origen la falacia política.

\section{Fase 2. Indicadores de producción de fake news y tipología de fuentes}

La influencia del mensaje de los representantes públicos sobre las audiencias a través de Twitter es un factor demostrado en investigaciones previas (Pérez Curiel y Limón Naharro, 2019), que la pandemia ha incrementado, dado el protagonismo de las redes sociales frente a los medios de comunicación tradicionales (Carlson, 2017; Casero-Ripollés, 2020).

En conexión con la segunda pregunta de investigación (PI2) se estudia el rol de las audiencias como productoras y viralizadoras de bulos. El número de mensajes falsos publicados en Twitter sobre la Covid-19, promovidos por los usuarios particulares, por delante de otras fuentes del ámbito de la política o de los medios de comunicación, es una característica que identifica la producción de contenidos en el periodo de investigación.

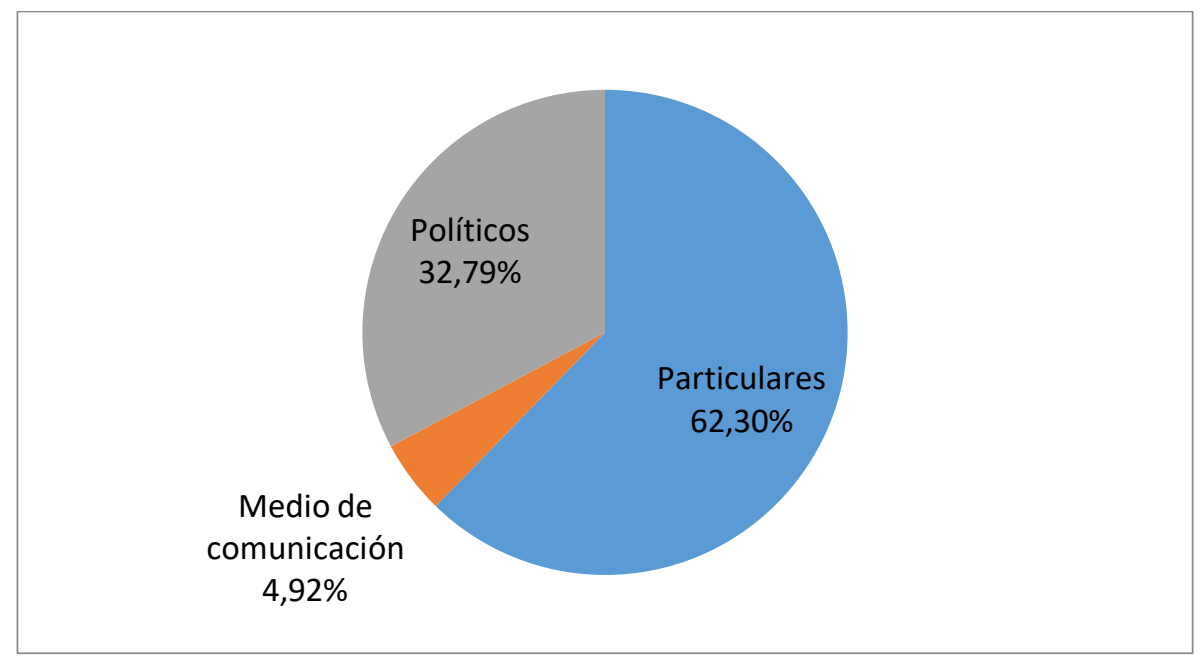

Gráfica 1. Fuentes y cuantificación comparada en la producción de bulos (\%)

Fuente: elaboración propia

Como reflejan los porcentajes (Gráfica 1), la relevancia de las fuentes particulares como autoras de información falsa $(62,30 \%)$ frente a otros actores como los políticos $(32,79 \%)$ o los medios de comunicación $(4,92 \%)$ es un rasgo definidor del comportamiento de las audiencias en situaciones de conflicto. Coincidiendo con estudios anteriores, las redes favorecen la producción de desórdenes informativos (Del Fresno García; 2019; Bakir y McStay, 2018), las fake news (Ghenai; Mejova, 2018; De-Keersmaecker y Roets, 2017) y el anonimato de los usuarios (Pérez Curiel y Velasco Molpeceres, 2020; Hernández-Santaolalla y Sola-Morales, 2019).

La mención a políticos y asuntos relacionados con declaraciones públicas de los representantes institucionales han sido objeto principal de los bulos, en un momento en el que las comparecencias

${ }^{16}$ https://elpais.com/espana/2020-03-21/sanchez-advierte-de-que-llega-la-ola-mas-duray-pide-fortaleza-y-unidad.html 
públicas para informar sobre el avance de la pandemia se multiplicaron en todos los países seleccionados como casos de estudio.

Tabla 4. Frecuencia de fuentes mencionadas y perfil de emisores de bulos

\begin{tabular}{|c|c|c|c|c|c|c|}
\hline \multicolumn{7}{|c|}{ Recuento } \\
\hline & & \multicolumn{4}{|c|}{ ¿A quién menciona en el bulo? } & \multirow[t]{2}{*}{ Total } \\
\hline & & $\begin{array}{l}\text { Presidentes } \\
\text { del } \\
\text { Gobierno }\end{array}$ & $\begin{array}{l}\text { Otros } \\
\text { miembros del } \\
\text { Gobierno }\end{array}$ & $\begin{array}{l}\text { Documentos } \\
\text { Oficiales/ } \\
\text { Ministeriales }\end{array}$ & Los políticos & \\
\hline \multirow{3}{*}{$\begin{array}{l}\text { Emisore } \\
\text { s } \\
\text { de } \\
\text { Bulos }\end{array}$} & Particulares & 10 & 3 & 14 & 11 & 38 \\
\hline & $\begin{array}{ll}\begin{array}{l}\text { Medio } \\
\text { comunicación }\end{array} & \mathrm{de} \\
\end{array}$ & 0 & 0 & 1 & 2 & 3 \\
\hline & Políticos & 7 & 1 & 4 & 8 & 20 \\
\hline \multicolumn{2}{|l|}{ Total } & 17 & 4 & 19 & 21 & 61 \\
\hline
\end{tabular}

\begin{tabular}{|c|c|c|c|}
\hline \multicolumn{4}{|l|}{ Pruebas de chi-cuadrado } \\
\hline & Valor & df & $\begin{array}{l}\text { Significación } \\
\text { asintótica } \\
\text { (bilateral) }\end{array}$ \\
\hline Chi-cuadrado de Pearson & $4,224^{\mathrm{a}}$ & 6 & ,646 \\
\hline Razón de verosimilitud & 5,138 & 6 & ,526 \\
\hline Asociación lineal por lineal &, 000 & 1 & ,999 \\
\hline $\mathrm{N}$ de casos válidos & 61 & & \\
\hline
\end{tabular}

Fuente: Elaboración propia

La situación de caos e inseguridad que define la primera etapa del coronavirus muestra un incremento de mensajes falsos (Tabla 4) que mencionan a los políticos en general (21), los documentos oficiales y ministeriales (19) o a los presidentes de gobierno (17). En concreto, son los usuarios particulares las fuentes que mayor número de bulos publican en Twitter (38), relacionados con boletines oficiales, órdenes, normas o decretos anunciados por las instituciones públicas (14), añadiendo información tergiversada y sin incluir enlaces que deriven a la fuente oficial. Otros focos de atención de estas cuentas son los políticos (11) y la figura del presidente del gobierno (10), convertido en primer portavoz institucional, por delante de otros cargos públicos.

Cuando la autoría del bulo corresponde a los políticos, se registra un interés por mencionar a otros políticos (8) y al máximo representante del Ejecutivo (7) recurriendo a críticas, errores o argumentos ficticios apoyados en la falacia y la propaganda. Provocar la confrontación y el conflicto responde a esquemas de juego político (horse-race), a ver quién gana en el escenario electoral (García Marín, Calatrava y Luengo, 2018; Reinemann y Wilke, 2007), una estrategia clave en la producción de bulos.

Tal y como muestran los datos, los miembros del Ejecutivo (ministros, portavoces o directores generales) no se han considerado fuentes referentes (4) de los mensajes falsos detectados por las agencias.

El término "Política" determina la selección de bulos publicados por las agencias de fact-checking, referidos a la Covid-19. Mediante tablas de contingencia, relacionamos la temática de los bulos con las fuentes productoras y emisoras de estos mensajes. La explotación de datos nos permite conocer 
qué asuntos han concentrado la mayor preocupación de las audiencias en Twitter, así como de los políticos y de los medios de comunicación.

Tabla 5. Contingencia de Temática y Fuentes de Bulos publicados por Agencias de Fact-checking

\begin{tabular}{|c|c|c|c|c|c|c|}
\hline \multirow{2}{*}{\multicolumn{3}{|c|}{ Temática }} & \multirow{2}{*}{\multicolumn{3}{|c|}{ Perfil de Fuentes }} & \multirow{3}{*}{$\begin{array}{l}\text { Total } \\
22 \\
\end{array}$} \\
\hline & & & & & & \\
\hline & \multirow{2}{*}{ Política y Políticos } & Recuento & $\begin{array}{l}\text { Particulares } \\
14\end{array}$ & $\begin{array}{l}\text { Medio de } \\
\text { comunicación } \\
2\end{array}$ & $\begin{array}{l}\text { Políticos } \\
6\end{array}$ & \\
\hline & & \% Autoría /Temática & $36,8 \%$ & $66,7 \%$ & $30,0 \%$ & $36,1 \%$ \\
\hline & \multirow{2}{*}{$\begin{array}{l}\text { Política } \\
\text { Internacional }\end{array}$} & Recuento & 3 & 0 & 0 & 3 \\
\hline & & \% Autoría/ Temática & $7,9 \%$ & $0,0 \%$ & $0,0 \%$ & $4,9 \%$ \\
\hline & \multirow[t]{2}{*}{ Política autonómica } & Recuento & 1 & 0 & 1 & 2 \\
\hline & & \% Autoría /Temática & $2,6 \%$ & $0,0 \%$ & $5,0 \%$ & $3,3 \%$ \\
\hline & \multirow{2}{*}{$\begin{array}{ll}\text { Fuerzas } & \text { de } \\
\text { Seguridad } & \end{array}$} & Recuento & 9 & 1 & 0 & 10 \\
\hline & & \%Autoría/Temática & $23,7 \%$ & $33,3 \%$ & $0,0 \%$ & $16,4 \%$ \\
\hline & \multirow[t]{2}{*}{ Economía } & Recuento & 3 & 0 & 1 & 4 \\
\hline & & \% Autoría /Temática & $7,9 \%$ & $0,0 \%$ & $5,0 \%$ & $6,6 \%$ \\
\hline & \multirow[t]{2}{*}{ Sanidad } & Recuento & 7 & 0 & 11 & 18 \\
\hline & & \% Autoría /Temática & $18,4 \%$ & $0,0 \%$ & $55,0 \%$ & $29,5 \%$ \\
\hline & \multirow[t]{2}{*}{ Educación } & Recuento & 1 & 0 & 0 & 1 \\
\hline & & \% Autoría /Temática & $2,6 \%$ & $0,0 \%$ & $0,0 \%$ & $1,6 \%$ \\
\hline & \multirow[t]{2}{*}{ Defensa } & Recuento & 0 & 0 & 1 & 1 \\
\hline & & \% Autoría/Temática & $0,0 \%$ & $0,0 \%$ & $5,0 \%$ & $1,6 \%$ \\
\hline \multirow{2}{*}{\multicolumn{2}{|c|}{ Total }} & Recuento & 38 & 3 & 20 & 61 \\
\hline & & \% Autoría /Temática & $100,0 \%$ & $100,0 \%$ & $100,0 \%$ & $100,0 \%$ \\
\hline
\end{tabular}

\begin{tabular}{|c|c|c|c|}
\hline \multicolumn{4}{|l|}{ Pruebas de chi-cuadrado } \\
\hline & Valor & df & $\begin{array}{l}\text { Significación } \\
\text { asintótica } \\
\text { (bilateral) }\end{array}$ \\
\hline Chi-cuadrado de Pearson & $18,071^{\mathrm{a}}$ & 14 & ,204 \\
\hline Razón de verosimilitud & 22,981 & 14 &, 061 \\
\hline Asociación lineal por lineal & 3,188 & 1 &, 074 \\
\hline $\mathrm{N}$ de casos válidos & 61 & & \\
\hline
\end{tabular}

Fuente: Elaboración propia

Según indican los valores obtenidos (Tabla 5), los temas más recurridos en los mensajes localizados por las agencias de fact-checking en Twitter son los relativos a Política y Políticos $(36,1 \%)$, Sanidad $(29,5 \%)$ y Fuerzas de Seguridad del Estado $(16,4 \%)$, lo que concuerda con la presencia continuada en los medios y en las redes de actores políticos procedentes de estos ámbitos. Si se observan los porcentajes y teniendo en cuenta el número de falsos publicados, los asuntos relacionados con la Política son el denominador común de los bulos de usuarios particulares $(36,8 \%)$ y de los propios políticos $(36,1 \%)$, seguidos por los contenidos relacionados con la Sanidad, un tema al que los líderes han dedicado un porcentaje significativo $(55,0 \%)$. Frente a otras fuentes, los medios de comunicación alcanzan niveles inferiores como autores de bulos (3/61), siendo la Política (66,7\%) y las Fuerzas de Seguridad (33,3\%) su máximo objetivo. Otros asuntos como Economía (6,6\%), Política Internacional (4,9\%), Política Autonómica (3,3\%) o Educación y Defensa (1,6\%) no destacaron como ejes de los bulos en la primera etapa de información de la pandemia. En fases posteriores, estos bloques aumentan su protagonismo en las redes y en los medios de comunicación, por las consecuencias y los efectos que provocan las decisiones gubernamentales. 
El cruce de datos revela una actitud de las fuentes que favorece la desinformación en momentos de crisis de la salud, un comportamiento ya analizado por estudios previos que tratan las limitaciones de Twitter para verificar rumores sobre emergencias (Laylavi et al., 2017; Stieglitz et al., 2018), teorías de conspiración política (Consentino, 2020) o desconfianza de la gente hacia los jefes de gobierno, políticos, funcionarios y medios de comunicación estatales, convertidos en propagadores de lo falso (Pérez Dasilva et al., 2020).

\section{Fase 3. Indicadores de verificación informativa en agencias y medios}

Urge en este escenario conocer los procedimientos de fact-checking que se aplican en la detección y tratamiento del fake, comprobar qué nivel de presencia alcanzan estas noticias en la prensa online y qué fórmulas de calidad periodística combaten la difusión de desinformación. Con objeto de responder a la tercera pregunta de investigación (PI3) estudiamos la función de verificación de agencias y medios de comunicación. En el caso de los fact-checkers de agencias se analizan las características de ubicación y formato de los bulos.

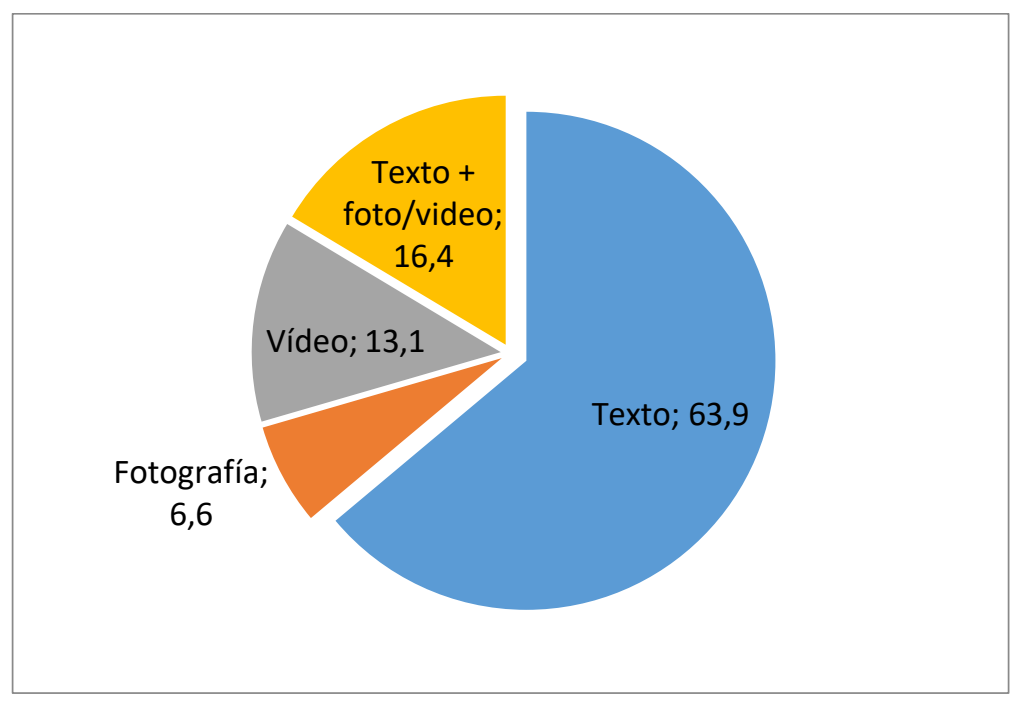

Gráfica 2. Frecuencia de aparición del bulo según su localización

Fuente: Elaboración propia

Tras el examen de títulos, texto completo y material multimedia adicional (fotos, vídeos, audios) de cada uno de los bulos verificados por las cuatro plataformas (Pagella Politica, Maldito Bulo, FullFact y Politifact), la Gráfica 2 constata que la mayor parte de la desinformación aparece en el texto del mensaje $(63,9 \%)$ por delante del vídeo $(13,1 \%)$, la fotografía $(6,6 \%)$ o la combinación de los tres formatos $(16,4 \%)$. Algunos ejemplos los observamos en las siguientes unidades de desinformación: 
PolitiFact $\otimes @$ PolitiFact. 25 mar.

Donald Trump claimed that recent American efforts to test widely for COVID-19 surpass those of other countries, specifically South Korea. That's wrong:

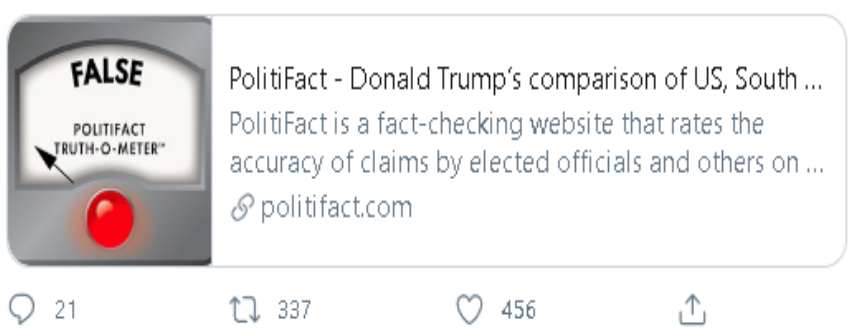

Imagen 5: Unidad de Desinformación en PolitiFact

Fuente: https://twitter.com/PolitiFact/status/1242935753799335936?s=20

PolitiFact denuncia el mensaje falso del presidente Donald Trump que defiende la supremacía y los esfuerzos de su gobierno para aplicar los tests de detección del coronavirus, frente a otros países como Corea del Sur (Imagen 5). La mayor parte de la información se concentra en el texto aunque, la agencia no se apoya en fuentes, antecedentes o datos de contexto que ayuden a demostrar la mentira.

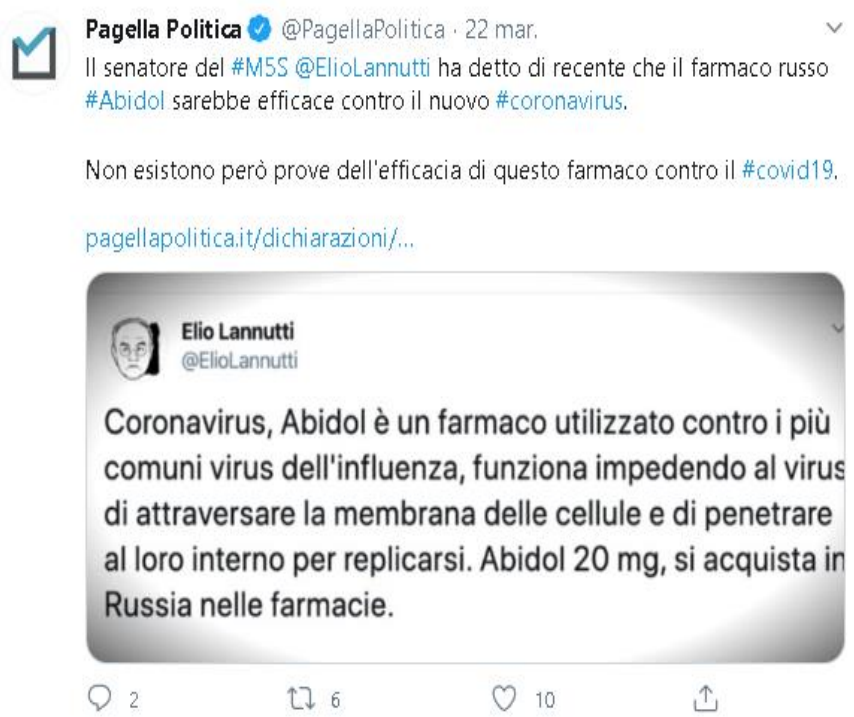

Imagen 6: Unidad de Desinformación en Pagella Politica

Fuente: https://twitter.com/PagellaPolitica/status/1241650828101832704?s=20

El texto (Imagen 6) hace referencia a una fake news publicada por Pagella Politica que denuncia como falsas las declaraciones del senador italiano Elio Lannutti, perteneciente al partido Movimiento Cinco Estrellas. El político asegura el éxito, no comprobado, de un fármaco contra el coronavirus, en línea con el discurso del presidente Conte en sus convocatorias públicas. La agencia de fact-checking confirma que no existen pruebas de la eficacia del fármaco. En este caso toda la información del bulo se concentra en el texto y no incluye fuentes ni argumentos de la agencia que justifiquen por qué el mensaje se considera falso. 
Otra de las técnicas utilizadas por los productores de bulos es el montaje audiovisual. Las agencias alertan de la falta de correspondencia de los hechos con el texto $(43,5 \%)$, con el lugar $(23,4 \%)$ o la fecha $(17,2 \%)$ de los acontecimientos, un factor que beneficia la reproducción de fakes en las redes y que se agrava en tiempos de crisis sanitaria (Salaverría et al., 2020)).

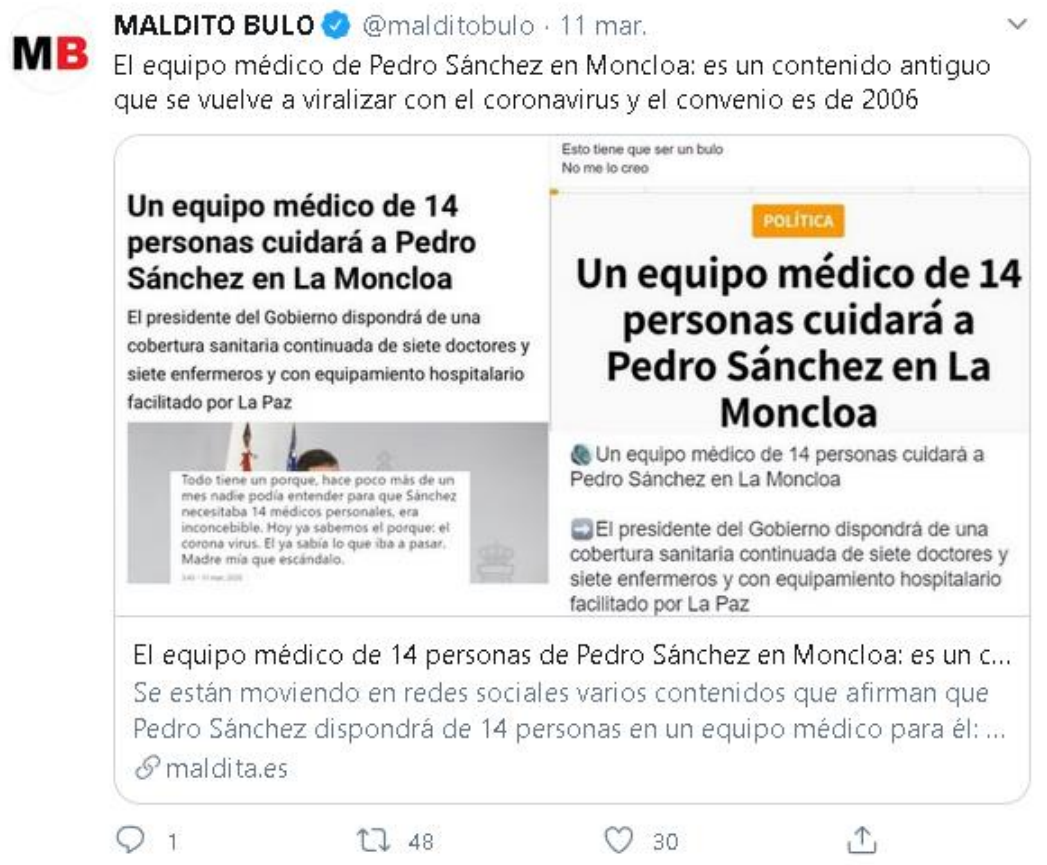

Imagen 7. Unidad de Desinformación de Maldito Bulo

Fuente: https://maldita.es/malditobulo/2020/03/12/equipo-medico-pedro-sanchez-moncloacoronavirus/

Maldito Bulo alerta de que el asunto del equipo médico de Pedro Sánchez en Moncloa corresponde a un contenido recogido en un convenio de 2006. En este caso, la agencia rescata la información antigua y argumenta el falso, aportando las pruebas.

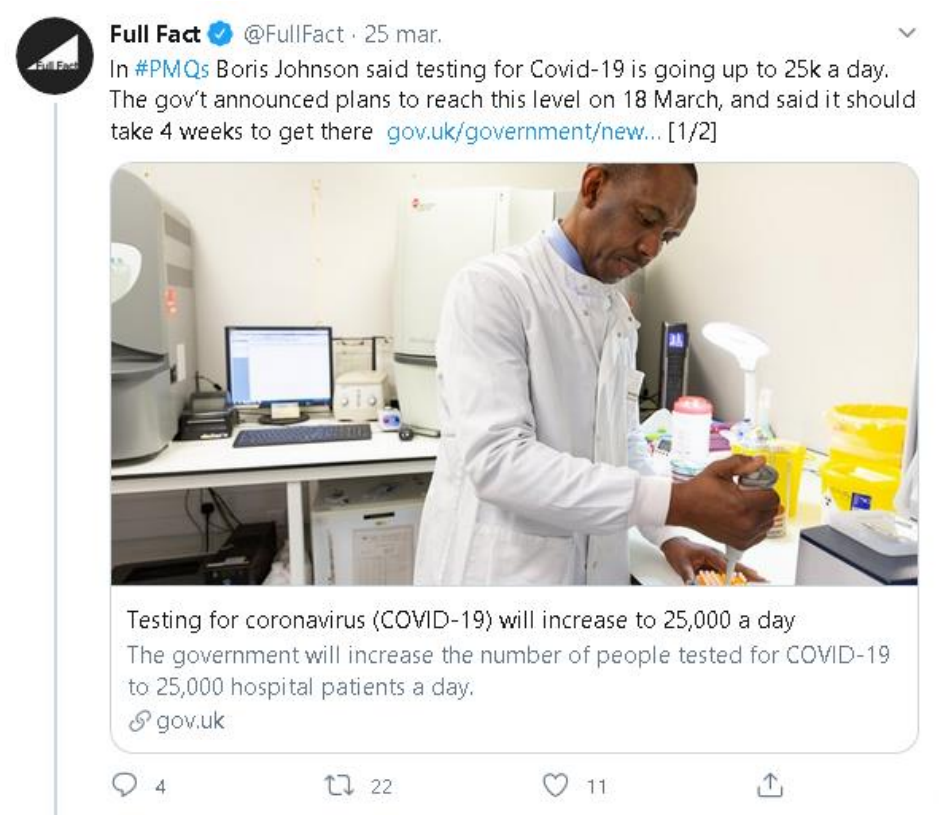

Imagen 8: Unidad de Desinformación en Full Fact

Fuente: https://twitter.com/FullFact/status/1242793645092352002?s=20 
De nuevo, la fake news se basa en declaraciones de políticos, en este caso de Boris Johnson, asegurando que se incrementarán los tests Covid-19 para la población británica. Se aportan datos y fechas que las agencias ponen en cuestión. Además, se usan recursos formales como fotografías o vídeos que no corresponden a los hechos reales.

En general, la dinámica de verificación de las agencias abunda en el uso de recursos formales, mediante subrayados, colores, usos de mayúsculas, marcas sobreimpresas o el uso del logo "Sin Pruebas" para constatar que no puede demostrarse la información. La cuestión es en qué medida la labor de las agencias contribuye más a la propagación de la mentira que a su desmentido, teniendo en cuenta que la denuncia de noticias falsas no siempre alcanza el impacto y la notoriedad que provoca la noticia original (Tuñón Navarro et al., 2019). El propio formato en red no facilita la verificación apoyada en la explicación, la interpretación y la aportación de pruebas que garanticen que los públicos tengan acceso a la información veraz (Vázquez Herrero, Vizoso y López García, 2019).

La fase de localización y denuncia del bulo requiere de acciones complementarias que de momento no han sido definidas por los fact-checkers de agencias. Desde esta perspectiva, interesa comprobar cómo se comportan los periódicos en cuanto al tratamiento de noticias falsas sobre la pandemia en el ámbito de la política (Lázaro-Rodríguez y Herrera-Viedma, 2020).

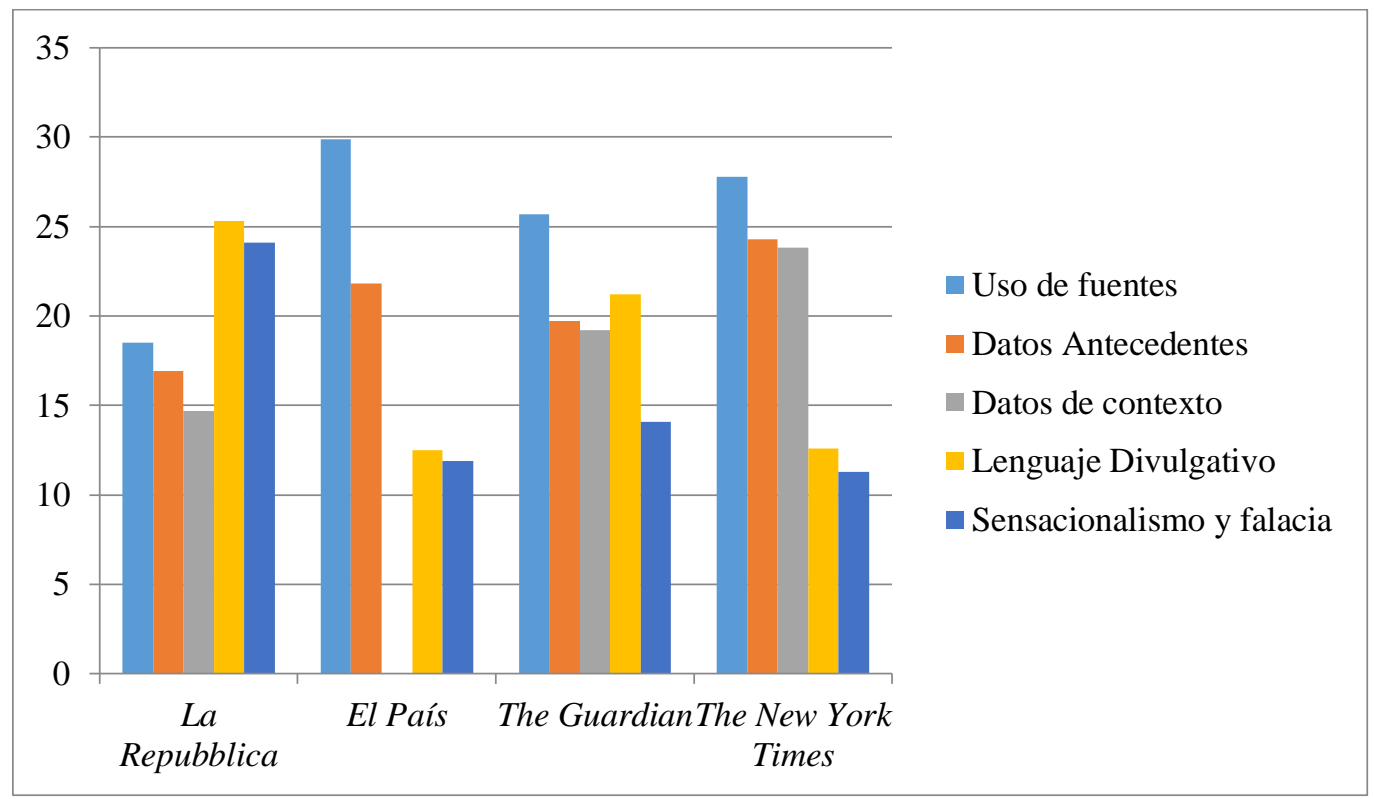

Gráfica 3: Catalogación de recursos aplicados a las noticias publicadas sobre Covid-19 Fuente: Elaboración propia

Perseguir y denunciar los bulos requiere aplicar unos registros de filtrado a los que se suman los recursos que potencian la credibilidad del relato: número y calidad de las fuentes, datos de background o antecedentes, datos de contexto y uso de un lenguaje divulgativo-explicativo que optimice la interpretación y el análisis crítico de las audiencias (Vázquez-Herrero et al., 2018).

Como muestra la Gráfica 3, el análisis del total de noticias publicadas en prensa (68), que hacen referencia a los bulos sobre política localizados por las agencias (61), confirma que la inclusión de fuentes expertas en distintos ámbitos es un rasgo característico que destaca en periódicos como $\mathrm{El}$ País (29,9\%), The New York Times (27,8\%) y The Guardian (25,7\%), frente al anonimato o la identificación de fuentes falsas en los bulos publicados en Twitter. Tanto The New York times como El País muestran valores significativos en el uso de antecedentes $(24,3 / 21,8 \%)$ y la contextualización 
de los hechos $(23,8 / 23,7)$ frente a un uso menos destacado del lenguaje divulgativo $(12,6 / 12,5 \%)$, que suele ser la tónica del discurso habitual de ambos medios. Frente a estos datos, periódicos como La Repubblica $(25,3 \%)$ o The Guardian $(21,2 \%)$ optan por un relato que, sin abandonar la amplia terminología técnica y científica vinculada a las epidemias, sea más accesible a los lectores digitales. En lo que respecta al bloque de sensacionalismo se detecta en el total de noticias un incremento de marcas de lenguaje falaz y de la propaganda en los textos de La Repubblica $(24,1 \%)$, una cabecera que en paralelo hace un uso más reducido del número de fuentes en la producción de noticias $(18,5 \%)$. En todos los casos, el uso de la falacia aparece vinculado especialmente a comparecencias de los políticos y presidentes de los gobiernos sobre la pandemia, que los periodistas intentan explicar apoyados en declaraciones de otras fuentes o mediante la explicación y la argumentación crítica de los mensajes.

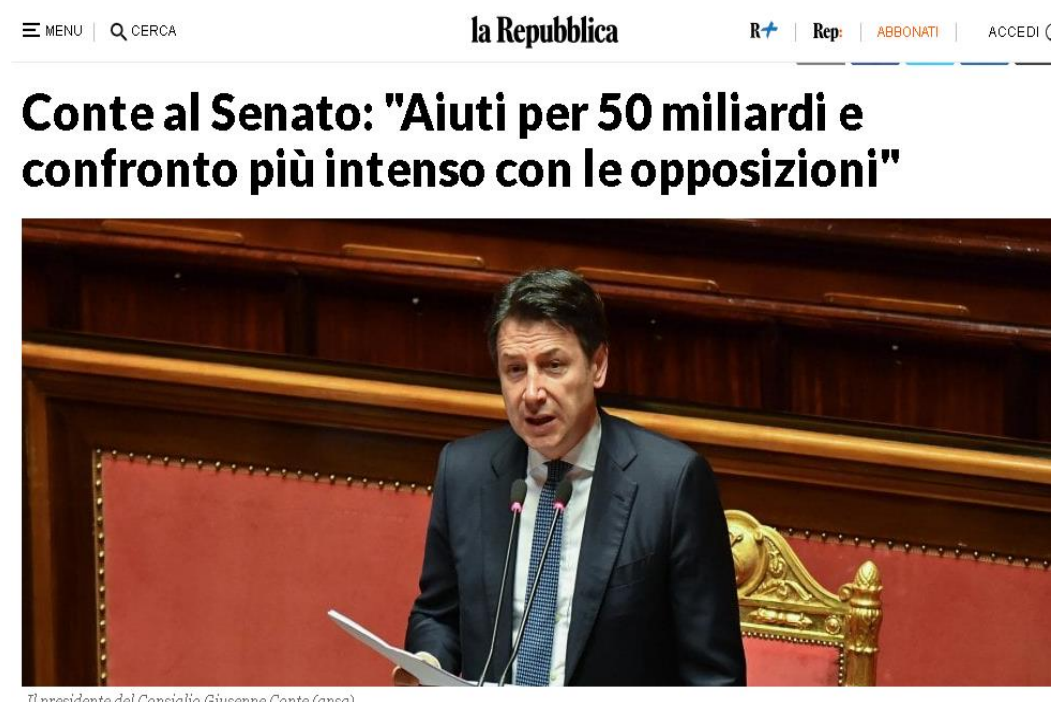

Imagen 9: Discurso de Conte ante el Senado atacando a la oposición

Fuente:

https://www.repubblica.it/politica/2020/03/26/news/conte_parlamento_renzi_fico_berlusconi$\underline{252349192 /}$

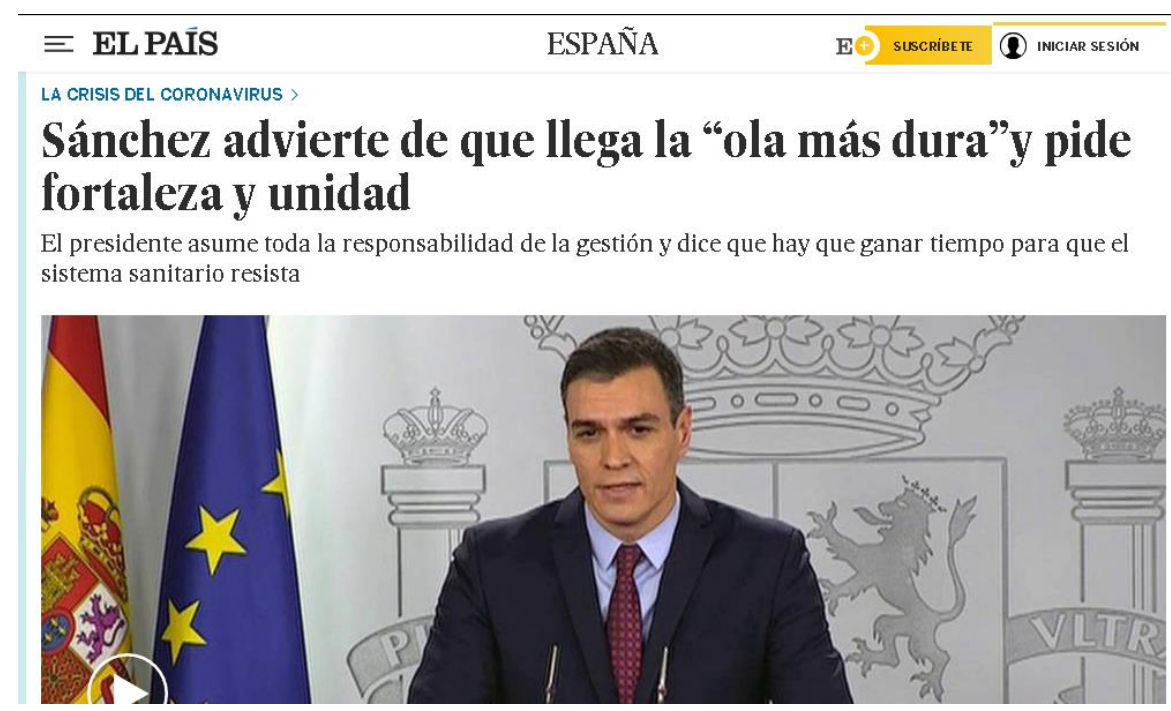

Imagen 10: Comparecencia de Pedro Sánchez antes de la declaración del Estado de Alarma Fuente: https://elpais.com/espana/2020-03-21/sanchez-advierte-de-que-llega-la-ola-mas-duray-pidefortaleza-y-unidad.html 


\section{Boris Johnson orders UK lockdown to be enforced by police}
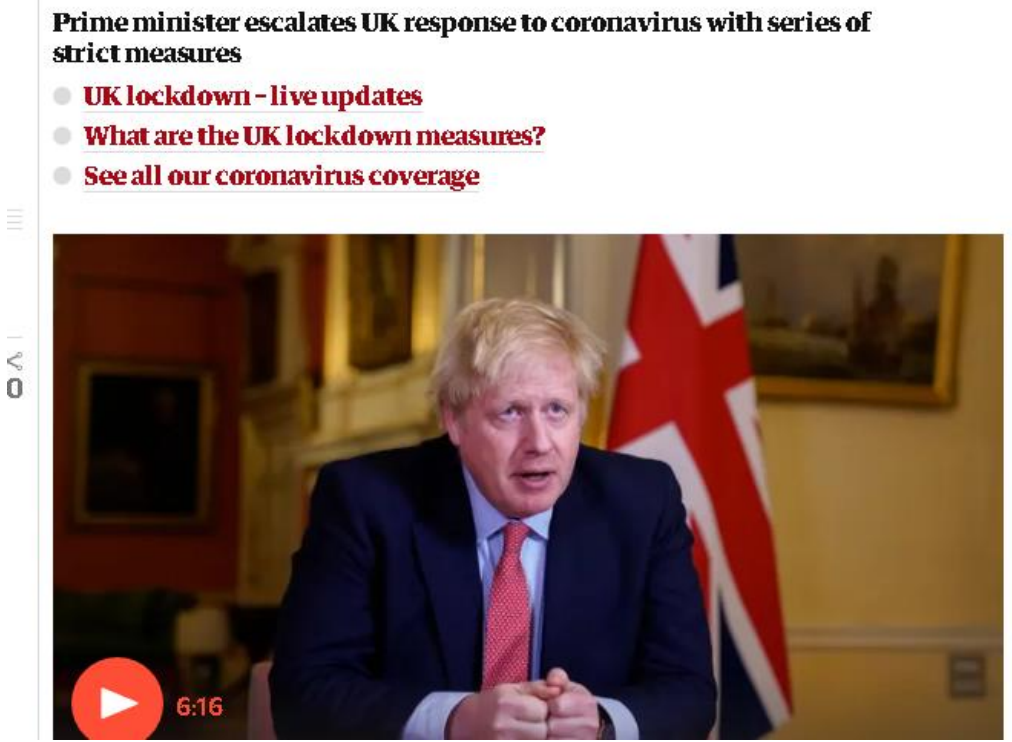

Imagen 11: El primer ministro británico ordena el cierre de fronteras de UK Fuente: https://www.theguardian.com/world/2020/mar/23/boris-johnson-orders-uk-lockdown-to-beenforced-by-police

\section{Trump's Baseless Claim That a Recession Would Be Deadlier Than the Coronaviru:}

The opposite is more likely to be true, according to research and experts.

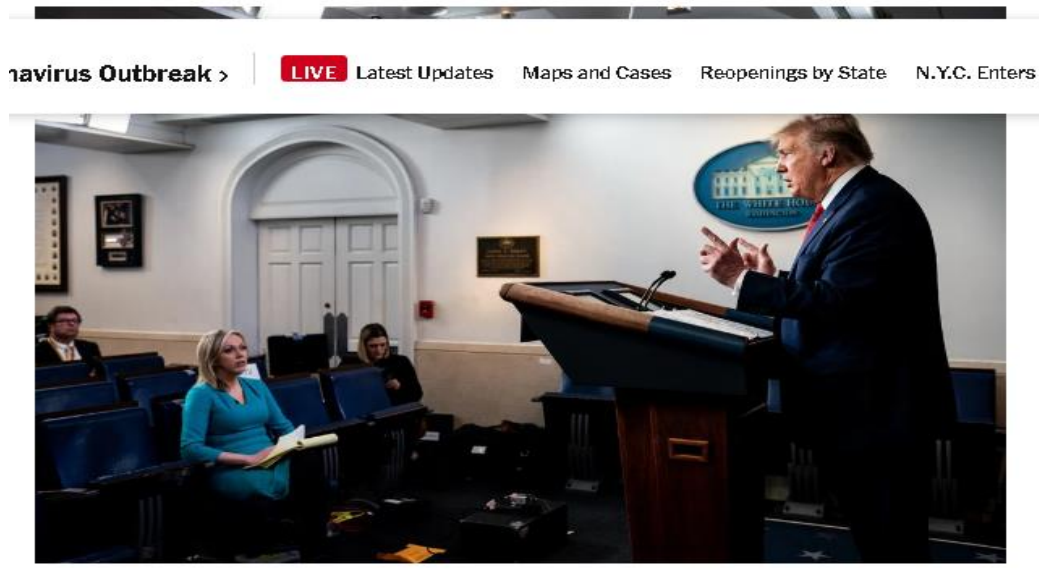

President Trump during a coronavirus briefing at the white House on Wednesday. Erin Schaff/The New York Times

Imagen 12: Donald Trump comparando los efectos de la recesión y el coronavirus Fuente: https://www.nytimes.com/2020/03/26/us/politics/fact-check-trump-coronavirusrecession.html?searchResultPosition $=7$ 
A pesar de que la Covid-19 se asocia con claves de emergencia sanitaria, la temática y tipología de fuentes procedentes de la política es una característica que comparten todos los periódicos y que coincide también con el perfil de actores de los bulos publicados por las agencias.

Frente a etapas previas en las que los medios tradicionales pierden audiencia, ingresos, credibilidad y autoridad (Carlson, 2017), dado el protagonismo y la influencia de las redes (Casero, 2020), la tendencia de la prensa digital en la cobertura del coronavirus denota una implementación de filtros sumada a un tratamiento periodístico analítico y crítico, que evite la confusión y detecte la mentira. No ha sido posible comprobar si los periódicos han eliminado noticias-bulo de su timeline en el caso de que se haya detectado el falso, lo que puede considerarse una limitación del sistema de difusión en red y de la propia investigación.

\section{Conclusiones}

Las estrategias de la comunicación política y la influencia del discurso de los líderes sobre el electorado y la ciudadanía a través de los medios y de las redes sociales se multiplican en situaciones de crisis de cualquier índole y origen (Casero-Ripollés, 2020). La Covid-19 es un ejemplo ilustrativo del comportamiento de los representantes políticos en las continuadas comparecencias públicas en una situación de inestabilidad política y económica, rodeada de inseguridad y confusión social (López García, 2020; Mantzarlis, 2018).

Aunque el uso de la retórica de la persuasión, de la falacia y la propaganda como rasgos identificadores del discurso político no es algo nuevo (Mancera Rueda \& Helfrich, 2014), durante la fase inicial de la propagación del coronavirus en el ámbito europeo y mundial, el incremento de las fake news y bulos en las redes sociales (Comisión Europea, 2020) ha sido objeto de debate y acusaciones entre los políticos (Salaverría et al., 2020; Waisbord, 2018).

El índice de falacia y propaganda de los mensajes publicados en Twitter por los presidentes de gobierno responde a una primera premisa (PI1) que identifica la desinformación como un rasgo propio del discurso político institucional. En todos los perfiles políticos analizados (Donald Trump, Boris Johnson, Giuseppe Conte y Pedro Sánchez), la cantidad y diversidad de falacias relacionadas con el virus, conduce a una seria reflexión sobre las consecuencias para una ciudadanía cada vez más expuesta a mensajes engañosos y en definitiva para la estabilidad democrática.

Sin embargo, en este escenario de viralización de los falsos, vinculados a la política y los políticos, destaca el rol de la audiencia social, como eje protagonista de la producción y difusión de rumores y bulos sobre el coronavirus. La desconfianza de los públicos hacia la política y los medios de comunicación tradicionales que, están perdiendo su preeminencia como principales fuentes de información sobre asuntos públicos (Bennett; Pfetsch, 2018) genera nuevos hábitos de consumo de noticias y cambia la forma en la que los ciudadanos atribuyen relevancia a la actualidad. Se crean comunidades de usuarios en las redes sociales que buscan información producida por sus propios pares, generalmente no contrastada ni verificada por los profesionales de los medios (Gil de Zúñiga et al, 2017). Al final de la cadena se sitúa con frecuencia un usuario que desconoce el origen y viraliza lo falso (Redondo, 2018).

Se confirma entonces una segunda premisa (PI2) que pone de relieve el papel de los ciudadanos como productores y consumidores (prosumers) de bulos sobre la pandemia, cooperando activamente con el desorden informativo que los políticos ya han provocado con sus comparecencias para informar sobre la Covid-19 y posteriormente con su difusión en Twitter. 
La identificación de los posibles actores de esa información errónea permitiría a las autoridades de la salud pública controlar el discurso de los medios de comunicación social, distinguir las deficiencias de las actuales estrategias de comunicación en torno a la salud, y detectar la información errónea antes de que pueda causar un daño irreparable (Pérez-Dasilva et al, 2020). En un campo como el de la salud, donde se agudizan los efectos de la desinformación (Ghenai; Mejova, 2018) es si cabe más importante la labor de verificación de las agencias de fact-checking y medios de comunicación. Asistimos a una crisis en la que las propias autoridades están demostrando niveles de desconocimiento a veces injustificados, que se solapan un discurso falaz, actuando de manera irresponsable y expandiendo en las redes un discurso que afecta más a las emociones que a la racionalidad (Boczkowski, 2016).

La función de detección y denuncia de bulos registrada por las agencias de fact-checkers (PolitiFact, Full Fact, Pagella Politica y MalditoBulo) responde más a un ejercicio de tratamiento de los contenidos mediante el uso de recursos formales que a una explicación en profundidad de las causas, el contexto, los antecedentes o la temporalización. De cara a las audiencias se hace necesario un procedimiento que ayude a localizar la mentira y desarrollar una actitud crítica ante los hechos, que evite convertir en viral una información no comprobada. Desde esta óptica se plantea una reflexión acerca de los procedimientos de control que ayude a localizar la mentira y desarrollar una actitud crítica ante los hechos, que evite convertir en viral una información no comprobada. Desde esta óptica se plantea una reflexión acerca de los procedimientos de las agencias de fact-ckecking como propulsoras de desinformación antes que como canalizadoras del desmentido, ante la indefensión, pasividad o alianza de las propias audiencias (Coromina y Padilla, 2018).

Para contrarrestar las debilidades de algunos modelos de verificación de agencias de fact-checking, y para reforzar la labor de gatekeeper que sigue identificando a los medios de comunicación, la tarea de control de bulos y fake news necesita de los periodistas como garantes de veracidad y contraste informativo. La transparencia, la credibilidad de las fuentes, la contextualización, la referencia a datos antecedentes que ayuden a los usuarios a diferenciar la verdad de la mentira (Palau Sampío, 2018) son valores que lejos de perder significado, se han reforzado como estrategias del periodismo para atajar los efectos de la falacia y el sensacionalismo (Journell, 2017; Allcott y Gentzkow, 2017). Frente a momentos de declive de los medios de comunicación abrumados por el surgimiento de nuevas narrativas y nuevos ritmos de producción de noticias provocados por las redes sociales (VanAelst et al., 2017), la respuesta de los profesionales de la información se reafirma en combatir toda la mentira que genera una situación de máxima confusión e inseguridad ciudadana.

En este marco, se confirma una tercera premisa (PI3) vinculada a la importancia del periodismo y de sus profesionales como expertos en la verificación y el contraste de fuentes que resista a la influencia de los políticos y de la ciudadanía como prosumidores de lo falso.

Ante una crisis inesperada a la que ni expertos, ni políticos ni medios han podido responder, proceden investigaciones futuras que, de la mano de las nuevas narrativas, la tecnología avanzada y la inteligencia artificial, analicen en qué medida la ciudadanía responderá a nuevos brotes, con comportamientos capaces de enfrentar una desinformación que sus mismos pares propagan y que intensifica un riesgo inminente para la democracia. 


\section{Bibliografía}

Adhanom-Ghebreyesus, T. \& Ng, A. (2020). Desinformación frente a medicina: hagamos frente a la 'infodemia'. El país, 18/02/2020. https://elpais.com/sociedad/2020/02/18/actualidad/1582053544 191857.html

Aleixandre-Benavent, R.; Castelló-Cogollos, L. \& Valderrama-Zurián, J.C. (2020). “Información_y comunicación durante los primeros meses de Covid-19. Infodemia, desinformación y papel de los profesionales de la información". El Profesional de la información, 29(4), e290408. https://doi.org/10.3145/epi.2020.jul.08

Allcott, H. \& Gentzkow, M. (2017). Social media and fake news in the 2016 election. Journal of economic perspectives, 31(2), 211-236. https://doi.org/10.1257/jep.31.2.211

Amat, F.; Arenas, A.; Falcó-Gimeno, A. \& Muñoz, J. (2020). Pandemics meet democracy. Experimental evidence from the Covid-19 crisis in Spain. SocArXiv, 6 de abril. https://doi.org/10.31235/osf.io/dkusw

Amoedo, A.; Vara-Miguel, A. \& Negredo, S. (2018). Digital news report.es 2018. Una audiencia diversa y preocupada por la desinformación. Universidad de Navarra. https://www.digitalnewsreport.es

Aparici, R.; García-Marín, D. \& Rincón-Manzano, L. (2019). Noticias falsas, bulos y trending topics. Anatomía y estrategias de la desinformación en el conflicto catalán. El profesional de la información, 28(3). https://doi.org/10.3145/epi.2019.may.13

Baker, P. (2006). Using corpora in discourse analysis. A\&C Black.

Bakir, V. \& McStay, A. (2018). Fake news and the economy of emotions: Problems, causes, solutions. Digital journalism, 6(2), 154-175. https://doi.org/10.1080/21670811.2017.1345645

Baym, N. K. (2010). Personal Connections in the Digital Age. Digital Media and Society Series. Cambridge: Polity

Beck, U. (2002). La sociedad del riesgo global. Siglo XXI.

Bennett, W. L. \& Pfetsch, B. (2018). Rethinking political communication in a time of disrupted public spheres. Journal of communication, 68(2), 243-253. https://doi.org/10.1093/joc/jqx017

Bernal-Triviño, A.; Clares-Gavilán, J. (2019). Uso del móvil y las redes sociales como canales de verificación de fake news. El caso de Maldita.es. El profesional de la información,28(3), e280312. https://doi.org/10.3145/epi.2019.may.12

Besalú Casademont, R. (2020). Enganxats a la tele: consum de televisió a Catalunya en temps de coronavirus.

https://repositori.upf.edu/bitstream/handle/10230/44212/Besalu_Audiencies_COVID_2020.pdf?se quence $=1 \&$ is Allowed $=\mathrm{y}$

Boczkowski, P. (2016). Las noticias falsas y el futuro del periodismo. La posverdad. Anfibia. Recuperado de: http://www.revistaanfibia.com/ensayo/la-postverdad/ 
Bradshwa, S. \& Howard, P. (2017): Troops, Trolls and Troublemakers: A Global Inventory of Organized Social Media Manipulation. Working paper no. 2017.12. en: https://comprop.oii.ox.ac.uk/wp-content/uploads/sites/89/2017/07/Troops-Trolls-andTroublemakers.pdf

Brennan, B. (2014). Una revisión general sobre comunicación de riesgos. https://cutt.ly/tyyMglk

Brennen, J. S.; Simon, F. M.; Howard, P. N. \& Nielsen, R. K. (2020). Types, sources, and claims of COVID-19 misinformation. Reuters Institute. Recuperado de https://reutersinstitute.politics.ox.ac.uk/types-sources-and-claims-covid-19-misinformation

Broniatowski, D. A.; Jamison, A. M.; Qi, S.; AlKulaib, L.; Chen, T.; Benton, A.; ... \& Dredze, M. (2018). Weaponized health communication: Twitter bots and Russian trolls amplify the vaccine debate. American journal of public health, 108(10), 1378-1384. https://doi.org/10.2105/AJPH.2018.304567

Campos-Domínguez, E. (2017). Twitter y la comunicación política. El profesional de la información, 26(5), 785-793. https://doi.org/10.3145/epi.2017.sep.01

Carlson, M. (2017). Journalistic authority: Legitimating news in the digital era. Columbia University Press.

Carrasco-Polaino, R.; Villar Cirujano, E. \& Tejedor Fuentes, L. (2018). Twitter como herramienta de comunicación política en el contexto del referéndum independentista catalán: asociaciones ciudadanas frente a instituciones públicas. Icono 14, 16(1), 64-85. https://doi.org/10.7195/ri14.v16i1.1134

Casero-Ripollés, A. (2020). Impacto del Covid-19 en el sistema de medios. Consecuencias comunicativas y democráticas del consumo de noticias durante el brote. El profesional de la información, 29(2). http://www.elprofesionaldelainformacion.com/contenidos/2020/mar/casero_es.html

Casero-Ripollés, A., Feenstra, R., \& Keane, J. (2016). La reconfiguración de la democracia: el laboratorio político español. Editorial Comares.

Casero-Ripollés, Andreu (2020). Influence of media on the political conversation on Twitter: Activity, popularity, and authority in the digital debate in Spain. Icono14. Revista cientifica de comunicación y tecnologías emergentes, 18(1), 33-57. https://doi.org/10.7195/ri14.v18i1.1527

CDC (2020). Pandemia H1N1 del 2009 (virus H1N1pdm09). https://espanol.cdc.gov/flu/pandemicresources/2009-h1n1-pandemic.html

Chadwick, L. \& Cereceda, R. (2020). La cloroquina e hidroxicloroquina contra el Covid-19 ¿Una esperanza?. Euronews, 7 abril. https:/les.euronews.com/2020/03/24/empiezan-los-ensayosclinicos-con-cloroquina-contra-el-covid-19-una-esperanza

Cheng, T. Y.-M.; Liu, L. \& Woo, B. K. (2018). Analyzing Twitter as a platform for Alzheimerrelated dementia awareness: Thematic analyses of tweets. JMIR aging, 1(2). https://doi.org/10.2196/11542 
Cherubini, F. \& Graves, L. (2016). The rise of fact-checking sites in Europe. Reuters Institute for the Study of Journalism, University of Oxford.

Chu, Z.; Gianvecchio, S.; Wang, H. \& Jajodia, S. (2012). Detecting automation of Twitter accounts: Are you a human, bot, or cyborg?. IEEE Transactions on dependable and secure computing, 9(6), 811-824. https://doi.org/10.1109/TDSC.2012.75

Cleary, M.; Horsfall, J. \& Hayter, M. (2014). Data collection and sampling in qualitative research: does size matter?. Journal of advanced nursing, 473-475. https://doi.org/10.1111/jan.12163

Centro Cochrane Iberoamericano (2020). ¿Cuál es la eficacia de la hidroxicloroquina en el tratamiento de la Covid-19?. Cochrane iberoamérica, 30 marzo. https://es.cochrane.org/es/\%C2\%BFcu\%C3\%A11-es-la-eficacia-de-la-hidroxicloroquina-en-eltratamiento-de-la-covid-19

Comisión Europea (2020). Lucha contra la desinformación. Comisión Europea. https://ec.europa.eu/info/live-work-travel-eu/health/coronavirus-response/fightingdisinformation es

Consejo Europeo (2020). Cronología: actuaciones del Consejo en relación con la Covid-19. Consejo de la Unión Europea. https://www.consilium.europa.eu/es/policies/covid-19-coronavirusoutbreak-and-the-eu-s-response/timeline

Congosto, M.; Basanta-Val, P. \& Sanchez-Fernandez, L. (2017). T-Hoarder: A framework to process Twitter data streams. Journal of Network and Computer Applications, 83, 28-39. https://doi.org/10.1016/j.jnca.2017.01.029

Coromina, Ò. \& Padilla, A. (2018). Análisis de las desinformaciones del referéndum del 1 de octubre detectadas por Maldito Bulo. Quaderns del CAC, 21(44), 17-26. Recuperado de https://www.cac.cat/sites/default/files/2019-01/Q44 Coromina Padilla ES.pdf

Cosentino, G. (2020). Social media and the post-truth world order. Springer International Publishing.

Costa-Sánchez, C. \& López-García, X. (2020). Comunicación y crisis del coronavirus en España. Primeras lecciones. El profesional de la información (EPI), 29(3), e290304. https://doi.org/10.3145/epi.2020.may.04

Dale, D. \& Talaga, T. (2016). Donald Trump: The unauthorized database of false things. Toronto Star, 4(11). Recuperado de https://www.thestar.com/news/world/uselection/2016/11/04/donaldtrump-the-unauthorized-database-of-false-things.html

De Keersmaecker, J. \& Roets, A. (2017). 'Fake news': Incorrect, but hard to correct. The role of cognitive ability on the impact of false information on social impressions. Intelligence, 65,107110, https://doi.org/10.1016/j.intell.2017.10.005.

Del-Fresno-García, M. (2019). Desórdenes informativos: sobreexpuestos e infrainformados en la era de la posverdad. El profesional de la información, 28(3). https://doi.org/10.3145/epi.2019.may.02 
Dredze, M.; Broniatowski, D. A. \& Hilyard, K. M. (2016). Zika vaccine misconceptions: A social media analysis. Vaccine, 34(30), 3441. https://doi.org/10.1016/j.vaccine.2016.05.008

El País (2020). Sánchez logra el apoyo del Congreso y convoca a un acuerdo nacional del que recela la oposición, El País, 9 abril. https://cutt.ly/fyTKjJx

Flick, U. (2004). Introducción a la investigación cualitativa. Morata.

Flowerdew, J., \& Richardson, J. E. (Eds.). (2017). The Routledge handbook of critical discourse studies. Taylor \& Francis.

García-Marín, J.; Calatrava, A. \& Luengo, Ó. G. (2018). Debates electorales y conflicto. Un análisis con máquinas de soporte virtual (SVM) de la cobertura mediática de los debates en España desde 2008. El profesional de la información, 27(3). https://doi.org/10.3145/epi.2018.may.15

Ghenai, A. \& Mejova, Y. (2017). Catching Zika fever: Application of crowdsourcing and machine learning for tracking health misinformation on Twitter. arXiv preprint arXiv:1707.03778. https://arxiv.org/abs/1707.03778

Ghenai, A. \& Mejova, Y. (2018). Fake cures: user-centric modeling of health misinformation in social media. Proceedings of the ACM on human-computer interaction, 2(CSCW), 1-20. https://arxiv.org/abs/1809.00557

Gil de Zúñiga, Homero; Weeks, Brian; Ardèvol-Abreu, Alberto (2017). Effects of the news-finds-me perception in communication: Social media use implications for news seeking and learning about politics. Journal of computer mediated communication, 22(3), 105-123. https://doi.org/10.1111/jcc4.12185

Gueham, F. (2017). Le fact-checking: une réponse à la crise de l'information et de la démocratie. Fondation

Guess, A., Nyhan, B. y Reifler, J. (2018). Selective Exposure to Misinformation. Evidence from the Consumption of Fake News during the 2016 US Presidential Campaign. European Research Council, 9(3), 4. Recuperado de http://www.ask-force.org/web/Fundamentalists/Guess-SelectiveExposure-to-Misinformation-Evidence-Presidential-Campaign-2018.pdf

Guidry, J. P., Jin, Y., Orr, C. A., Messner, M., \& Meganck, S. (2017). Ebola on Instagram and Twitter: How health organizations address the health crisis in their social media engagement. Public relations review, 43(3), 477-486. https://doi.org/10.1016/j.pubrev.2017.04.009

Hallin, C. \& Mancini, P. (2004). Comparing media systems. Three models of media and politics. Cambridge University Press.

Hansen, Mark; Roca-Sales, Meritxell; Keegan, Jonathan M.; King, George (2017). Artificial untelligence: Practice and implications for journalism. Columbia University Libraries; Tow Center for Digital Journalism.

Harsin, J. (2018). A critical guide to fake news: From comedy to tragedy. Pouvoirs. Revue française d'études constitutionnelles et politiques, (164), 99-119. http://www.revue-pouvoirs.fr/A-CriticalGuide-to-Fake-News-From.html 
Hernández-Santaolalla, V. \& Sola-Morales, S. (2019). Postverdad y discurso intimidatorio en Twitter durante el referéndum catalán del 1-O. Observatorio (OBS*), 13(1), 102-121. https://doi.org/10.15847/obsOBS13120191356

Holtz-Bacha, C. (2003). Comunicación política: entre la privatización y la espectacularización. Diálogo político, 1, 137-154.

Jamison, A. M.; Broniatowski, D. A. \& Quinn, Sandra-Crouse (2019). Malicious actors on Twitter: A guide for public health researchers. American journal of public health, 109(5), 688-692. https://doi.org/10.2105/AJPH.2019.304969

Journell, W. (2017). Fake news, alternative facts, and Trump: Teaching social studies in a post-truth era. Social studies journal, 37(1), 8-21. http://www.uncg.edu/ awjourne/Journell2017ssj.pdf

Kaiser, B. (2020). I blew the whistle on Cambridge Analytica - four years later, Facebook still hasn't learnt its lesson. The Independent. https://www.independent.co.uk/voices/us-election-trumpcambridge-analytica-facebook-fake-news-brexit-vote-leave-a9304421.html

Krippendorff, K. (2004). Content analysis. Sage.

Kupferschmidt, K. (2020). Preprints bring 'firehose' of outbreak data. Science, 367(6481), 963-964. http://doi.org/10.1126/science.367.6481.963

Larson, H. J. (2020). "Blocking information on Covid-19 can fuel the spread of misinformation". Nature, 580(306). https://doi.org/10.1038/d41586-020-00920-w

Laylavi, F.; Rajabifard, A. \& Kalantari, M. (2017). Event relatedness assessment of Twitter messages for emergency response. Information processing \& management, 53(1), 266-280. https://doi.org/10.1016/j.ipm.2016.09.002

Lázaro-Rodríguez, Pedro; Herrera-Viedma, Enrique (2020). "Noticias sobre Covid-19 y 2019-nCoV en medios de comunicación de España: el papel de los medios digitales en tiempos de confinamiento". El profesional de la información, v. 29, n. 3, e290302. https://doi.org/10.3145/epi.2020.may.02

Lee, S. \& Xenos, M. (2019). Social distraction? Social media use and political knowledge in two US Presidential elections. Computers in human behavior, 90, 18-25. https://doi.org/10.1016/j.chb.2018.08.006

López-Borrull, A.; Vives-Gràcia, J. \& Badell, J-I. (2018). Fake news, ¿amenaza u oportunidad para los profesionales de la información y la documentación? El profesional de la información, 27(6), 1346-1356. https://doi.org/10.3145/epi.2018.nov.17

López-García, G. (2020). Vigilar y castigar: el papel de militares, policías y guardias civiles en la comunicación de la crisis del Covid-19 en España. El profesional de la información, 29(3), e290311. https://doi.org/10.3145/epi.2020.may.11

Magallón-Rosa, R. (2018). Nuevos formatos de verificación. El caso de_Maldito Bulo en Twitter, Sphera Publica, 1(18), 41-65. http://sphera.ucam.edu/index.php/sphera-01/article/view/341 
Mancera Rueda, A. \& Helfrich, U. (2014). La crisis en 140 caracteres: el discurso propagandístico en la red social Twitter. Cultura, Lenguaje y Representación, 12, 59-86. http://www.erevistes.uji.es/index.php/clr/article/view/1385

Mantzarlis, A. (2018). Fact-checking 101. En: C. Ireton \& J. Posetti (Eds.), Journalism, fake news \& disinformation: Handbook for journalism education and training (85-100). Unesco. Recuperado de https://en.unesco.org/sites/default/files/journalism_fake_news_disinformation_print_friendly_0.pdf

Marcos-Recio, J.C (2017). "Verificar para mejorar la información en los medios de comunicación con fuentes documentales". Hipertext.net, 15, 36-45. https://doi.org/10.2436/20.8050.01.44

Mayo-Cubero, M. (2020). News sections, journalists and information sources in the journalistic coverage of crises and emergencies in Spain. El profesional de la información (EPI), 29(2), e290211. https://doi.org/10.3145/epi.2020.mar.11

Naderi, N., \& Hirst, G. (2018). Automated fact-checking of claims in argumentative parliamentary debates. En Proceedings of the First Workshop on Fact Extraction and VERification (FEVER) (pp. 60-65). http://dx.doi.org/10.18653/v1/W18-5509

Neuendorf, K. A. (2002). Defining content analysis. Content analysis guidebook. Sage.

Newman, N., Fletcher, R., Kalogeropoulos, A., \& Nielsen, R. (2019). Reuters Institute digital news report 2019 (Vol. 2019). Reuters Institute for the Study of Journalism. Recuperado de https://reutersinstitute.politics.ox.ac.uk/our-research/digital-news-report-2019

Nielsen, R.-K.; Fletcher, R.; Newman, N.; Brennen, J. S. \& Howard, P. (2020). Navigating the 'Infodemic': How people in six countries access and rate news and information about coronavirus. Reuters Institute for the Study of Journalism. https://cutt.ly/ryTKzYp

Nielsen, R.K. y Graves, S. (2017). News you don't believe: Audience perspective on fake news. Reuters Institute for the Study of Journalism. Retrieved from https://reutersinstitute.politics.ox.ac.uk/ourresearch/news-you-dont-believe-audienceperspectives-fake-news

Nocetti, Ó. (1990). Falacias y Medios de Comunicación. El discurso como arma. Editorial Humanitas.

OMS (2020). Covid-19: cronología de la actuación de la OMS. OMS. https://www.who.int/es/newsroom/detail/08-04-2020-who-timeline---covid-19

Palau-Sampio, D. (2018). Fact-checking y vigilancia del poder: La verificación del discurso público en los nuevos medios de América Latina. Communication \& Society, 31(3), 347-363. https://doi.org/10.15581/003.31.3.347-363

Panetta, K. (2017). Gartner top strategic predictions for 2018 and beyond. Gartner. https://www.gartner.com/smarterwithgartner/gartner-top-strategic-predictions-for-2018-andbeyond 
Patwari, A, Goldwasser, D. y Bagchi, S. (2017). TATHYA. A multi-classifier system for detecting check-worthy statements in political debates. En: Proceedings of the 2017 ACM Conference on Information and Knowledge Management. https://dl.acm.org/citation.cfm?id=3133150

Pérez-Curiel, C. \& Velasco Molpeceres, A. M. (2020). Tendencia y narrativas de fact-checking en Twitter. Códigos de verificación y fake news en los disturbios del Procés (14-O), Adcomunica, (20), 95-122. http://www.adcomunicarevista.com/ojs/index.php/adcomunica/article/view/671

Pérez-Curiel, C. \& Limón Naharro, P. (2019). Influencers de la Política. Estudio de la marca personal de Donald Trump en Twitter y efectos en medios y usuarios. Communication \& Society, 32(1), 57-76. https://doi.org/10.15581/003.32.1.57-76

Pérez-Dasilva, J.-Á.; Meso-Ayerdi, K. \& Mendiguren-Galdospín, T. (2020). Fake news y coronavirus: detección de los principales actores y tendencias a través del análisis de las conversaciones en Twitter. El profesional de la información, 29(3), e290308. https://doi.org/10.3145/epi.2020.may.08

Powers, S. \& Kounalakis, M. (eds.). (2017). Can Public Democracy Survive the Internet? Bots, Echo Chambers, and Disinformation. U.S. Advisory Commission on Public Diplomacy (Department of State).

Redondo, M. (2016). La doctrina del post. Posverdad, noticias falsas...Nuevo lenguaje para desinformación clásica. ACOP: https://compolitica.com/la-doctrina-del-post-posverdad-noticiasfalsas-nuevo-lenguaje-para-desinformacion-clasica/

Reinemann, C. \& Wilke, J. (2007). It's the Debates, Stupid! How the Introduction of Televised Debates Changed the Portrayal of Chancellor Candidates in the German Press, 1949-2005. Harvard International Journal of Press/Politics, 12(4), 92-111. https://doi.org/10.1177\%2F1081180X07307185

Rodríguez Andrés, R. (2018). Fundamentos del concepto de desinformación como práctica manipuladora en la comunicación política y las relaciones internacionales. Historia y comunicación social, 23(1), 231-244. https://doi.org/10.5209/HICS.59843

Rodríguez-Fernández, L. (2019): "Desinformación y comunicación organizacional: estudio sobre el impacto de las fake news". Revista Latina de Comunicación Social, 74, 1714-1728. http://www.revistalatinacs.org/074paper/1406/89es.html

Rosen, G. (2020). "An update on our work to keep people informed and limit misinformation about Covid-19”. 16 April 2020. https://about.fb.com/news/2020/04/covid-19-misinfo-update

Salaverría, R.; Buslón, N.; López-Pan, F.; León, B.; López-Goñi, I. \& Erviti, M. C. (2020). Desinformación en tiempos de pandemia: tipología de los bulos sobre la Covid-19. El profesional de la información, 29(3), e290315. https://doi.org/10.3145/epi.2020.may.15

Shearer, E. \& Gottfried, J. (2017). News use across social media platforms 2017. Pew Research Center, 7(9). https://internet.psych.wisc.edu/wp-content/uploads/532-Master/532-UnitPages/Unit05/Gottfried_PewResearch_2017.pdf 
Silverman, D. (Ed.). (2016). Qualitative research. Sage.

Stahl, K. (2018). Fake news detection in social media. California State University Stanislaus, 6.

Stieglitz, S.; Bunker, D.; Mirbabaie, M. \& Ehnis, C. (2018). Sense-making in social media during extreme events. Journal of Contingencies and Crisis Management, 26(1), 4-15. https://doi.org/10.1111/1468-5973.12193

Tandoc, E. C. (2020). Commentary: how to stay sane in a time of Covid-19 information overload. Channel new Asia, 4 April. https://www.channelnewsasia.com/news/commentary/covid-19coronavirus-information-overload-fake-newshoaxes-12595334

Torres-Salinas, D. (2020). Ritmo de crecimiento diario de la producción científica sobre Covid-19. Análisis en bases de datos y repositorios en acceso abierto. El profesional de la información, 29(2), e290215. https://doi.org/10.3145/epi.2020.mar.15

Tuñón Navarro, J., Oleart, Á., \& Bouza García, L. (2019). Actores Europeos y Desinformación: la disputa entre el factchecking, las agendas alternativas y la geopolítica. Revista de comunicación, 18(2), 245-260. https://doi.org/10.26441/RC18.2-2019-A12

Van Dijk, T. (2015). Critical discourse studies. A sociocognitive Approach. Methods of Critical Discourse $\quad$ Studies, 3(1), 63-74. https://www.researchgate.net/publication/265620660 Critical Discourse Studies A Sociocogniti ve_Approach_1

Van-Aelst et al. (2017) Political communication in a high-choice media environment: a challenge for democracy? Annals of the International Communication Association, 41(1), 3-27. https://doi.org/10.1080/23808985.2017.1288551

Vázquez-Herrero, J.; Vizoso, A. \& López-García, X. (2019). Innovación tecnológica y comunicativa para combatir la desinformación: 135 experiencias para un cambio de rumbo. El profesional de la información, 28(3). https://doi.org/10.3145/epi.2019.may.01

Vosoughi, Soroush; Roy, Deb; Aral, Sinan (2018). "The spread of true and false news online". Science, 359(6380), 1146-1151. https://doi.org/10.1126/science.aap9559

Wang, T.; Brede, M.; Ianni, A. \& Mentzakis, E. (2017). Detecting and characterizing eating-disorder communities on social media. En: Proceedings of the Tenth ACM International conference on web search and data mining, (91-100). https://doi.org/10.1145/3018661.3018706

Wardle, C. (2017). Fake news. It's complicated. First Draft, 16.

Wardle, C., \& Derakhshan, H. (2017). Information disorder: Toward an interdisciplinary framework for research and policy making. Council of Europe report, 27. https://rm.coe.int/informationdisorder-toward-an-interdisciplinary-framework-for-researc/168076277c

Weedon, J.; Nuland, W. \& Stamos, A. (2017). Information operations and Facebook. https://fbnewsroomus.files.wordpress.com/2017/04/facebook-and-information-operations-v1.pdf 
Xifra, J. (2020). Comunicación corporativa, relaciones públicas y gestión del riesgo reputacional en tiempos del Covid-19. El profesional de la información (EPI), 29(2), e290220. https://doi.org/10.3145/epi.2020.mar.20

Zimdars, M. (2016). False, misleading, clickbait and/or satirical news sources. https://21stcenturywire.com/wp-content/uploads/2017/02/2017-DR-ZIMDARS-False-

MisleadingClickbait-y-and-Satirical-\%E2\%80\%9CNews\%E2\%80\%9D-Sources-Google-Docs.pdf

\section{AUTORES:}

\section{Concha Pérez Curiel}

Doctora en Periodismo por la Universidad de Sevilla. Imparte docencia de Periodismo Político en Grado y en los Másteres de Comunicación Institucional y Política y de Estudios Europeos (US). Pertenece al grupo de investigación Communication \& Social Sciences (SEJ-619) y es miembro de los proyectos Influencers en la comunicación política en España. Análisis de las relaciones entre líderes de opinión 2.0, medios de comunicación, partidos, instituciones y audiencias en el entorno digital (CSO2017-88620-P) y DEBATv, Debates Electorales Televisados en España: Modelos, Proceso, Diagnóstico y Propuesta" (CSO2017-83159-R), financiados por el Ministerio de Ciencia, Innovación y Universidades de España. Investiga sobre comunicación política, influencia y transferencia de agendas, nuevas narrativas digitales y efectos en los medios y los usuarios. Entre sus publicaciones destacan trabajos en El Profesional de la Información, Latina. Revista de Comunicación Social, Communication and Society o Kome y en editoriales de referencia como Routledge.

cperez1@us.es

Índice H: 8

Orcid ID: https://orcid.org/0000-0002-1888-0451

Google Scholar: https://scholar.google.es/citations?hl=es\&user=wyp6bucAAAAJ

ResearchGate: https://www.researchgate.net/profile/Concha Perez-Curiel

Academia.edu: https://us.academia.edu/ConchaP\%C3\%A9rezCuriel

Scopus: https://www.scopus.com/authid/detail.uri?authorId=57192428906

\section{Ana María Velasco Molpeceres}

Doctora en comunicación por la Universidad de Valladolid, donde es profesora. Licenciada en Periodismo, Máster en Comunicación, Graduada en Historia del Arte y en Geografía e Historia y Posgrado en Comunicación audiovisual. Ha sido investigadora predoctoral FPU y es miembro del proyecto "Europeísmo y redes trasatlánticas en los siglos XX y XXI" (PGC2018-095884-B-C22), financiado por fondos FEDER. Trabaja sobre identidades en los medios de comunicación, comunicación política, influencia, moda y nuevas narrativas digitales y efectos sobre los medios y los usuarios, así como historia de la comunicación y estudios de género. Entre sus publicaciones destacan trabajos en revistas científicas como Historia y comunicación social, Prisma social, Observatorio o Revista de Occidente, así como varios libros.

anamaria.velasco.molpeceres@uva.es

Índice H: 3

Orcid ID: http://orcid.org/0000-0002-0593-0325

Google Scholar: https://scholar.google.com/citations?user=xPnUDmUAAAAJ

Academia.edu: https://uva-es.academia.edu/AnaVelasco 
